\title{
THE
}

\section{The Use of Omega-3 Fatty Acids in Mental Illness}

Jessica L. Gören

University of Rhode Island, jgoren@challiance.org

T. Tewksbury

Follow this and additional works at: https://digitalcommons.uri.edu/php_facpubs

Terms of Use

All rights reserved under copyright.

\section{Citation/Publisher Attribution}

Gören, J. L., \& Tewksbury, A. T. (2011). The Use of Omega-3 Fatty Acids in Mental Illness. J. of Pharmacy Practice, 24(5), 452-471. doi: 10.1177/0897190011422876

Available at: http://dx.doi.org/10.1177/0897190011422876

This Article is brought to you for free and open access by the Pharmacy Practice at DigitalCommons@URI. It has been accepted for inclusion in Pharmacy Practice Faculty Publications by an authorized administrator of DigitalCommons@URI. For more information, please contact digitalcommons-group@uri.edu. 


\title{
Journal of Pharmacy Practice
}

The Use of Omega-3 Fatty Acids in Mental Illness

Jessica L. Gören and Ashley T. Tewksbury

Journal of Pharmacy Practice published online 22 September 2011

DOI: $10.1177 / 0897190011422876$

The online version of this article can be found at:

http://jpp.sagepub.com/content/early/2011/09/22/0897190011422876

\author{
Published by: \\ (A) SAGE
}

http://www.sagepublications.com

On behalf of:

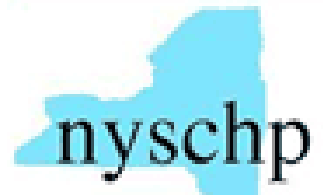

New York State Council of Health-system Pharmacists

Additional services and information for Journal of Pharmacy Practice can be found at:

Email Alerts: http://jpp.sagepub.com/cgi/alerts

Subscriptions: http://jpp.sagepub.com/subscriptions

Reprints: http://www.sagepub.com/journalsReprints.nav

Permissions: http://www.sagepub.com/journalsPermissions.nav

>> Version of Record - Sep 22, 2011

What is This? 


\title{
The Use of Omega-3 Fatty Acids in Mental Illness
}

Journal of Pharmacy Practice

$000(00) \mathrm{I}-20$

(C) The Author(s) 2011

Reprints and permission:

sagepub.com/journalsPermissions.nav DOI: I0.1 |77/0897| 900 | | 422876

http://jpp.sagepub.com

@SAGE

\author{
Jessica L. Gören, PharmD, BCPP ${ }^{1,2,3}$ and Ashley T. Tewksbury, BS ${ }^{4}$
}

\begin{abstract}
Purpose: This article will summarize the current evidence on the effects of omega- 3 fatty acids on prevention and treatment of mental illness. Background: Omega-3 fatty acids are involved in many physiologic processes. Since they cannot be made de novo in the body, they are considered essential nutrients. As the Western diet evolved, dietary intake of fatty acids has shifted to increased omega- 6 fatty acids and decreased omega-3 fatty acids intake. These changes have been correlated with numerous differences in prevalence and course of mental illnesses. Methods: A MEDLINE search from 1966 to December 2010 was completed to identify studies comparing changes in symptoms, functioning, other outcomes, and/or side effects in patients treated with omega-3 fatty acids for mental illness. The studies were reviewed and reported by specific psychiatric disorder studied. Conclusions: Omega-3 fatty acids play a role in many biologic functions. Epidemiologic data implicate omega-3 fatty acid deficiencies in many mental illnesses. Data are most robust for omega-3 fatty acids' role in affective disorders. However, data are conflicting, negative, or absent for most mental illnesses.
\end{abstract}

\section{Keywords}

omega-3, fatty acids, omega-6, mental illness, polyunsaturated

\section{Introduction}

Fatty acids can be divided into 2 categories, based on chemical properties (1) saturated fatty acids, which are usually solid at room temperature and (2) unsaturated fatty acids, which are liquid at room temperature. Carbon atoms in saturated fats are bound to 4 other atoms and cannot bind with other atoms. Unsaturated fatty acids can bind with other atoms due to double bonds linking at least 1 pair of carbon.

Based on the number of double bonds present, unsaturated fatty acids are either monounsaturated (contains 1 double bond) or polyunsaturated (containing $>1$ double bond). Plant oils such as olive and canola oils are made up of monounsaturated fatty acids. Vegetable-, nut-, and seed-based oils such as corn, sunflower, walnut, and flax seed oils consist of polyunsaturated fatty acids (PUFAs). Polyunsaturated fats are further defined by the location of the first double bond. Omega- 6 fatty acids' double bonds begin at the sixth carbon atom, while omega-3 fatty acids' double bonds begin with the third carbon atom. Examples of omega- 6 fatty acids are the short chain linoleic acid (LA) and the longer chain gamma linoleic (GLA) and arachidonic (AA) acids. Omega-3 fatty acids include alphalinolenic acid (ALA), a short chain omega-3 fatty acid, and long chain omega-3 fatty acids eicosapentaenoic (EPA), docosapentaenoic acid (DPA), and docosahexaenoic (DHA).

The human body cannot make the short chain ALA and LA fatty acids, and so they are considered essential nutrients. The long chain omega-6 (GLA and AA) and omega-3 fatty acids (EPA, DPA, and DHA) can be formed in the body from LA and
ALA. However, only $10 \%$ to $15 \%$ of ALA can be converted into EPA, DPA, or DHA in vivo. ${ }^{1}$ Therefore, the majority of long-chain fatty acids are derived from dietary sources. ${ }^{1-4,7-9}$ When a person is deficient in omega- 3 fatty acids, there is increased incorporation of omega- 6 fatty acids in cell membranes leading to stiffer, less flexible cell membranes. ${ }^{1-3,7-10}$ Thus, the ratio of omega- 6 fatty acids to omega- 3 fatty acids is essential for normal neuronal functioning.

PUFAs are precursors of eicosanoids, a group of bioactive mediators involved in inflammation, immunity, and coagulation (Figure 1). ${ }^{2}$ Series 1 prostaglandins and thromboxanes and series 4 leukotrienes are derived from AA. AA-derived eicosanoids respond to stress or injury producing an array of effects on clotting, muscle contractility, and cellular influx/efflux of substances such as calcium. These effects are modulated by the EPA-derived series 3 prostaglandins and thromboxanes and series 5 leukotrienes. EPA-derived eicosanoids have less potent effects or prevent the effects of AA-derived eicosanoids. Thus,

\footnotetext{
' Department of Pharmacy Practice, College of Pharmacy, University of Rhode Island, Kingston, RI, USA

${ }^{2}$ Cambridge Health Alliance, Boston, MA, USA

${ }^{3}$ Harvard Medical School, Boston, MA, USA

${ }^{4}$ Northeastern University, Boston, MA, USA
}

\section{Corresponding Author:}

Jessica L. Gören, Department of Pharmacy Practice, College of Pharmacy, University of Rhode Island, I44 Lower College Road, Kingston, RI 0288I, USA Email: jgoren@challiance.org 


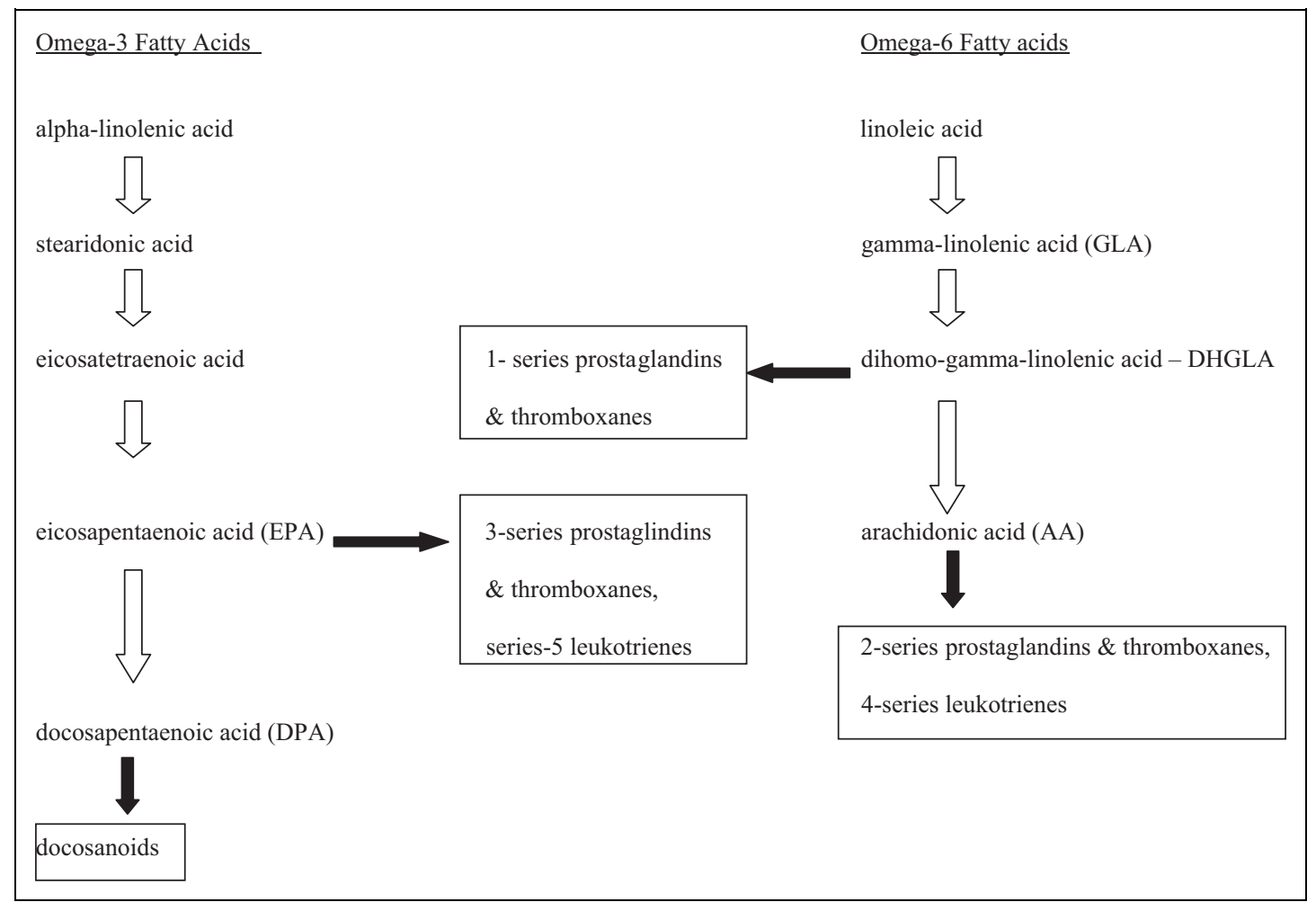

Figure I. Polyunsaturated fatty acids.

adequate production of EPA-derived eicosanoids is necessary for proper functioning of AA-derived eicosanoids. ${ }^{1-7}$

DHA is converted into the docosanoids, a group of bioactive molecules possessing anti-inflammatory and neuroprotective properties. Resolvins, one type of docosanoids, are important in counteracting proinflammatory responses to omega- 6 fatty acids. $^{4-7}$ Consequently this cytoprotective function is also heavily dependent on the omega- 6 to omega- 3 ratio.,

DHA is an integral component of neuronal development and maturation. ${ }^{1,2,8}$ Consequently, DHA is an important fatty acid for learning and neuronal growth and development during the fetal and infant stages. ${ }^{3}$ Maternal DHA deficiency during pregnancy and lactation may lead to lower cognitive performance later in childhood.

Neuronal membrane fluidity is dependent on the type of fatty acid incorporated into the cell membrane. DHA and EPA are incorporated into neuronal cell membranes and allow the membrane to be fluid or "flexible." Such membrane fluidity is necessary for proper functioning of lipid messengers which signal cascades leading to changes in neuronal flexibility and function. This is important in psychiatric illnesses because serotonin and catecholamine receptors, ion channels, transporters, and G-coupled proteins are dependent on fluid or flexible cell membranes.

Omega-3 fatty acids are also involved in many physiologic processes outside the central nervous system. EPA and DHA enhance nitric oxide production, which may be responsible for improved endothelial function and arterial compliance. ${ }^{11,12}$ Alterations in the metabolism of adhesion molecules by DHA and EPA may inhibit new arterial plaque development. ${ }^{13,14}$ Inhibition of voltage-gated sodium channels may account for reductions in arrhythmias with omega-3 fatty acid supplementation. ${ }^{15}$ While omega-3 fatty acids influence platelet aggregation, recent studies have failed to find a correlation between omega-3 fatty acids and coagulation factors. ${ }^{16}$ Although earlier studies have reported omega- 3 fatty acids affect platelet aggregation through reductions in thromboxane, a proaggregatory eicosanoid and inhibition of cyclooxygenase enzymes associated with thrombosis. ${ }^{17}$ However, the US Food and Drug Administration (FDA) has designated omega-3 fatty acids as "generally recognized as safe" when taken at normal doses. ${ }^{18}$ Taken together, omega-3 fatty acid appears to be safe and beneficial in cardiac disease. ${ }^{18}$

The source of omega-3 fatty acids is important. Epidemiologic data indicate both plant- (ALA) and marine (DHA and EPA)-derived omega-3 fatty acids are important for physiologic processes. ${ }^{19}$ However, the preponderance of data indicate fish-derived omega-3 fatty acids are preferable to plantderived omega- 3 fatty acids. This is reflected in the American Psychiatric Association's recommendations that (1) all adults eat a variety of fish (preferably oily fish) 2 or more times weekly; (2) patients with mood, impulse-control, and psychotic disorders consume $1 \mathrm{~g}$ of EPA + DHA daily; and (3) a supplement may be useful in patients with mood disorders. ${ }^{19}$

Since omega- 3 fatty acids are essential nutrients, changes in diet can have profound effects on omega-3 fatty acid concentrations. The ratio of omega- 6 to omega- 3 fatty acid intake has shifted dramatically in the Western diet over several decades. 
Currently in many Western countries the omega- 6 to omega-3 intake ratio is $10: 1$, while a ratio of $1: 1$ may be more appropriate. ${ }^{16}$ Given omega-3 fatty acids' beneficial effects on multiple neuronal and cardiovascular targets, it is not surprising that dietary changes are implicated in both psychiatric and cardiovascular disorders.

\section{Methods}

In order to determine whether omega fatty acids are a reasonable treatment option for psychiatric disorder, we conducted a systematic review of the medical literature. In January 2011, we conducted a MEDLINE search from 1966 to December 2010 to identify studies of omega-3 fatty acids as treatment or prevention of psychiatric illnesses. The following search terms were used: omega-3 fatty acid, eicosapentaenoic (EPA), docosahexaenoic (DHA), mental illness, psychiatry, affective and mood disorders, psychosis, schizophrenia, anxiety, substance abuse, attention-deficit hyperactivity disorder (ADHD), autism, Asperger's, bipolar disorder, depression, perinatal and postpartum depression, and personality disorder. The reference section of these articles and previous reviews were searched for articles not identified in the original search. Articles were restricted to the English language. Data on study design, PUFA treatment, and side effects were abstracted and reported.

We examined studies within strata reflecting the rigor of their study design: randomized controlled trials (RCTs), nonrandomized controlled studies, and noncontrolled observational studies. Because of the robust number of studies with one of these designs, we excluded case reports and series without statistical analyses. Major limitations of each study are noted in the evidence tables; these include small sample sizes in some studies, limited matching characteristics, and short periods before follow-up assessment. Unless otherwise noted, all comparisons reported were statistically significant.

\section{Unipolar Depression}

Most epidemiologic data support the link between fish consumption and a lowered risk of depression. ${ }^{20-28}$ Consumption of seafood at least twice a week may be associated with a lower risk of depression and suicidal ideation. ${ }^{23,24}$ Severity of depressive symptoms has been linked to the omega- 6 to omega- 3 ratio. ${ }^{25,26}$ Many studies suggest a link between depression and reduced omega-3 fatty acid concentrations in plasma, serum phospholipids, and red blood cells. ${ }^{21-28}$ The one large trial that failed to replicate these findings may have been confounded by the high average daily intake of omega- 3 fatty acids across the population. ${ }^{29}$ Studies report mixed outcomes for the interaction of gender and omega-3 fatty acid concentrations on depression. One study reported increased fish intake was associated with less depression in women but not men, ${ }^{20}$ while another study found depression was inversely related to omega- 3 intake in boys aged 12 to 15 years. ${ }^{28}$

Antidepressant response has been postulated to be associated with omega-3 fatty acid concentrations, although results from clinical trials have been mixed (Table 1). ${ }^{30-45}$ Of the 7 augmentation studies in adults, 4 found no benefit with the addition of omega-3 fatty acids..$^{30,31,32,35}$ However, 2 of these studies were in patients with comorbid diabetes or coronary heart disease and may not be applicable for depressed patients without these comorbidities. ${ }^{30,31}$ The 2 positive placebocontrolled studies reported a 7.2- to 10.8-point improvement on the Hamilton Depression Rating scale (HAMD) compared with placebo. ${ }^{33,36}$ The 1-dose finding trial reported significant benefit only in the low-dose $(1 \mathrm{~g})$ group. ${ }^{34}$

Of the 8 double-blind trials of omega- 3 fatty acids as monotherapy for depression, 6 were placebo controlled. ${ }^{39-41,43-45}$ One randomized, double-blind trial compared omega- 3 fatty acids, fluoxetine and the combination. ${ }^{38}$ The remaining randomized trial was a dose finding trial and did not include a placebo group.

Five of the trials, including the largest study, reported no benefit of omega-3 fatty acids in depression. ${ }^{39-41,43,45}$ However, one of the negative trials studied "mental well-being" in those $\geq 65$ years and another studied psychological distress. ${ }^{39,45}$ Both may not adequately address the use of omega3 fatty acids in patients with major depression. The remaining trials differed significantly in terms of specific omega- 3 fatty acids and dose studied, making generalization problematic. One trial included fluoxetine as an active comparator. ${ }^{38}$ The authors reported $1 \mathrm{~g}$ of EPA and $20 \mathrm{mg}$ fluoxetine had similar effects, while the combination was superior to either alone.

The final controlled study of omega- 3 fatty acids was a dose finding study of DHA in adults with depression. ${ }^{42}$ Doses included were 1, 2, and $4 \mathrm{~g}$ daily. All 3 doses were beneficial but the most improvement was seen on the 1-g dose, suggesting there may be a ceiling effect of DHA supplementation.

The only RCT in children was omega-3 fatty acid augmentation of ongoing antidepressant treatment. ${ }^{37}$ The population was predominately male. The study found significant benefit on all outcome measures. The authors point out that the study had an unexpectedly low placebo response rate which may have affected the results.

The role of omega-3 fatty acids in unipolar depression is promising. Epidemiologic data support the theory that omega-3 fatty acid deficiency is associated with increased rates of depression. However, clinical trials report varied outcomes. This may be due to the heterogeneity of trials reported in the literature. Studies differed in which omega-3 fatty acid or combinations of fatty acids were used. Augmentation trials typically enrolled patients regardless of their baseline antidepressant. Doses studied varied widely, with total daily doses up to $9.6 \mathrm{~g}$. A wide variety of depressive disorders were studied including major depressive disorder, less severe forms of depression, and depression with comorbid medical illnesses. Although most studies were in adult patients, age groups studied ranged from pediatric to geriatric populations. In addition, trials reported on outcomes of omega-3 fatty acid monotherapy, omega-3 fatty acid augmentation of specific antidepressant, and combinations of any pre-study antidepressant and omega-3 fatty acids. While doses ranged widely, all studies 


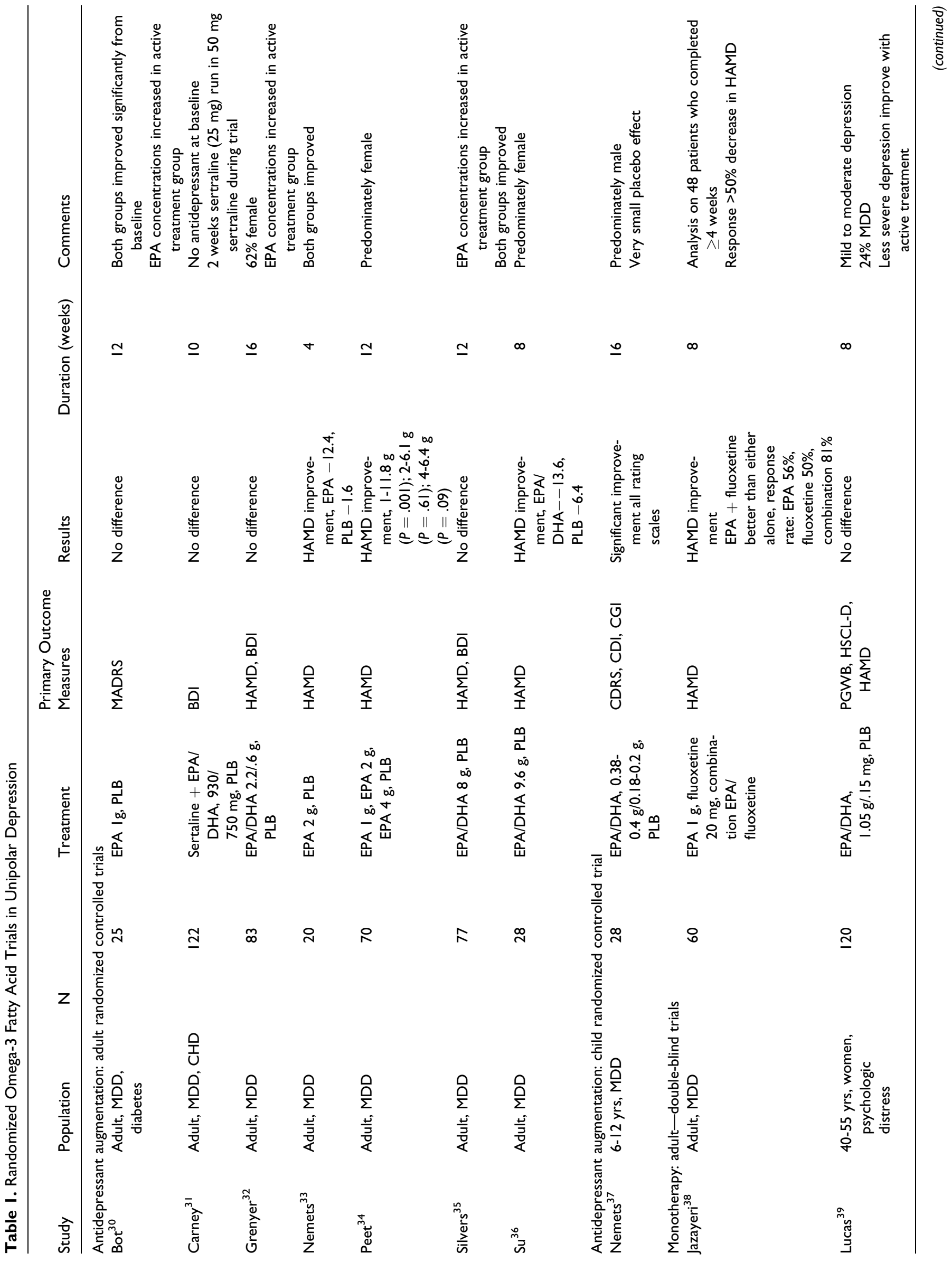




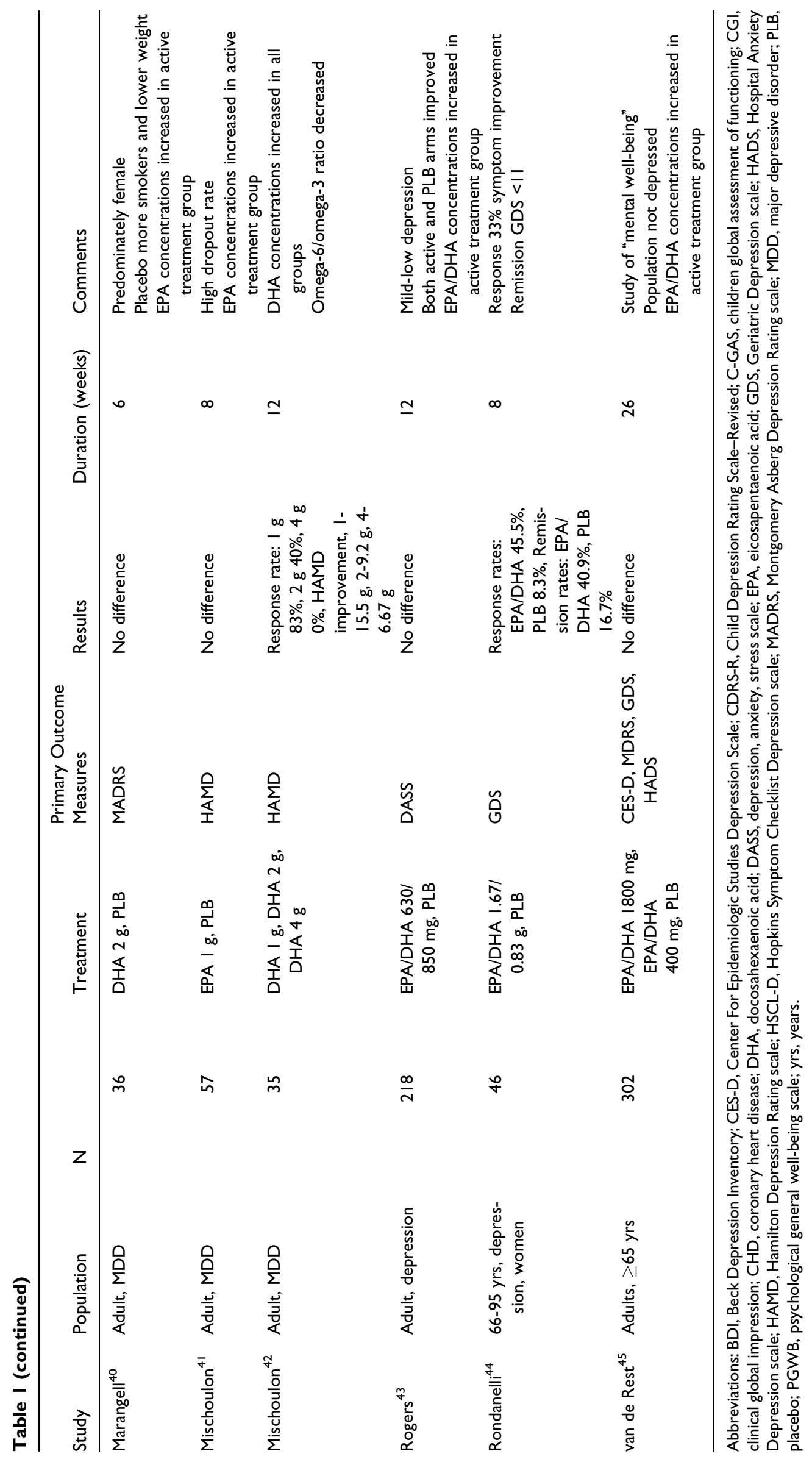


Journal of Pharmacy Practice 000(00)

reported the use of EPA, DHA, or their combination, so fish-derived omega-3 fatty acids would seem to be preferable to plant-derived ALA.

While it is difficult to draw any firm conclusions about omega-3 fatty acids in unipolar depression, given the safety, cardioprotective effects, and suggestion that there may be some benefits with omega-3 fatty acid augmentation or monotherapy in depression, it seems reasonable to consider omega-3 fatty acids as a treatment option for patients with depression. They have a potential role as antidepressant augmentation or monotherapy for adults in whom antidepressants are not acceptable. Given the disparity of data, it is difficult to recommend specific doses or combinations of fatty acids. It has been suggested that EPA may be the effective component in depression treatment. ${ }^{46}$ But, animal models suggest that DHA-deficient diets are associated with abnormal dopaminergic and serotonergic function. ${ }^{47}$ Clinical trial data suggest that higher doses may not confer additional benefits and a daily total of omega-3 fatty acids (EPA/DHA) of 1 to $2 \mathrm{~g}$ is reasonable in unipolar depressive illnesses. While the one trial of omega- 3 fatty acids in children was positive, it is premature to recommend its use as a therapeutic option in pediatric depression. However, since omega-3 fatty acids have been proven safe in many other pediatric conditions, it is unlikely their use in pediatric populations would be harmful.

\section{Perinatal Depression}

Normal neurodevelopment in utero is dependent on adequate supply of DHA. ${ }^{1,2,8}$ Hibbeln and Davis suggest that during pregnancy, as DHA is transferred to the fetus, women with low-DHA intake will become depleted and more vulnerable to depression. ${ }^{48}$ This is supported by epidemiologic data indicating higher intake of fish during pregnancy is associated with decreased risk of postpartum depression. ${ }^{49,50}$ Countries with low fish intake have a 50 -fold increased risk of postpartum depression compared with countries with high seafood intake. ${ }^{49}$ Single women with low seafood intake who smoke may be more likely to have depressive symptoms during pregnancy. ${ }^{51}$ Still other studies report lower concentrations of DHA in women who develop postpartum depression than those who do not. ${ }^{50}$ Some studies have failed to find an association of omega-3 fatty acid intake and perinatal depression. One study of 80 women was probably underpowered to find a relationship, while another study had relatively high-baseline rates of seafood consumption. ${ }^{51,52}$ The largest study, a prospective cohort study of 54202 Danish women, did not support the inverse relationship of fish or omega-3 fatty acid intake and postpartum depression. ${ }^{53}$

Potential risk of low DHA intake extends beyond mothers to their offspring. Lower verbal intelligence quotient (IQ), increased risk of fine motor deficits, and behavioral problems have been reported in children born to women with low seafood intake during pregnancy. ${ }^{54,55}$ Hibbeln and Davis calculated $900 \mathrm{mg} / \mathrm{d}$ per 2000 calories from seafood is likely sufficient to provide optimal neurodevelopment in the offspring and decrease the risk of postpartum depression. ${ }^{48}$ They also report that there is no evidence indicating an upper limit of intake for omega-3 fatty acids as there are no data indicating an excess of omega-3 fatty acids contribute to neurodevelopment or psychiatric risks.

Interventional trials of omega-3 fatty acid supplementation during pregnancy have reported mixed outcomes (Table 2). ${ }^{56-62}$ Six randomized studies were placebo controlled and 1 was a randomized dose ranging study.

Freeman et al reported significant benefit of omega-3 fatty acid supplementation in women randomized to 1 of 3 doses of EPA and DHA. ${ }^{57}$ However, the study lacked a placebo group and was not confirmed in more rigorous trials. Llorente and colleagues found 16 weeks of $200 \mathrm{mg}$ was not associated with changes in rates of postpartum depression. ${ }^{59}$ However, the study had a low baseline level of depression in both groups and of those with depressive symptoms at baseline, the majority reported only mild symptoms. Four other RCTs also failed to find the benefits of omega-3 fatty acid supplementation on depressive symptoms, ${ }^{56,58,60,61}$ while 1 small trial reported benefit with DHA supplementation. ${ }^{62}$

The largest randomized, double-blind, placebo-controlled trial found supplementation with $900 \mathrm{mg} / \mathrm{d}$ of omega-3 fatty acids did not prevent postpartum depression in 2399 women. ${ }^{60}$ During the trial, women were supplemented with omega- 3 fatty acids during the second half of pregnancy. Adherence was confirmed by increased concentrations of DHA in the cord blood of women in the active treatment arm compared with controls ( $7.2 \%$ vs $6.09 \% ; P<.001)$. The results may have been confounded by an unusually low rate of maternal depression in the control group. The authors did report a nonsignificant trend toward decreased depression in women who had been previous medically diagnosed with depression.

While the role of omega-3 fatty acids in perinatal depression is supported by epidemiologic data, this has not been born out in interventional trials. The largest study of omega-3 fatty acid supplementation in pregnancy failed to find an effect of omega-3 fatty acids in perinatal depression. This study utilized a dose consistent with the $900 \mathrm{mg} / \mathrm{d}$ per 2000 calories suggested by researchers as likely to meet the nutritional requirements for $97.5 \%$ of pregnant women. ${ }^{48}$ These findings are in direct contrast to some groups recommending routine omega-3 fatty acid supplementation for pregnant women. However, it is important to remember the risk to the fetus and some data indicate poor cognitive outcomes in children born to women with low omega-3 fatty acid intake. Overall, while the benefit of omega-3 fatty acids in perinatal depression, primarily DHA, is not supported by controlled trials, it is likely that normal neurocognitive development is dependent upon adequate maternal DHA concentrations. Given the safety of omega- 3 fatty acids, effects in fetal development and general medical benefits such as improved cardiovascular health, DHA supplementation during pregnancy is reasonable. While there are no clear guidelines as to dose, Hibbeln and Davis' work support the use of $900 \mathrm{mg} / \mathrm{d}$ per 2000 calories of DHA during pregnancy. ${ }^{48}$ 


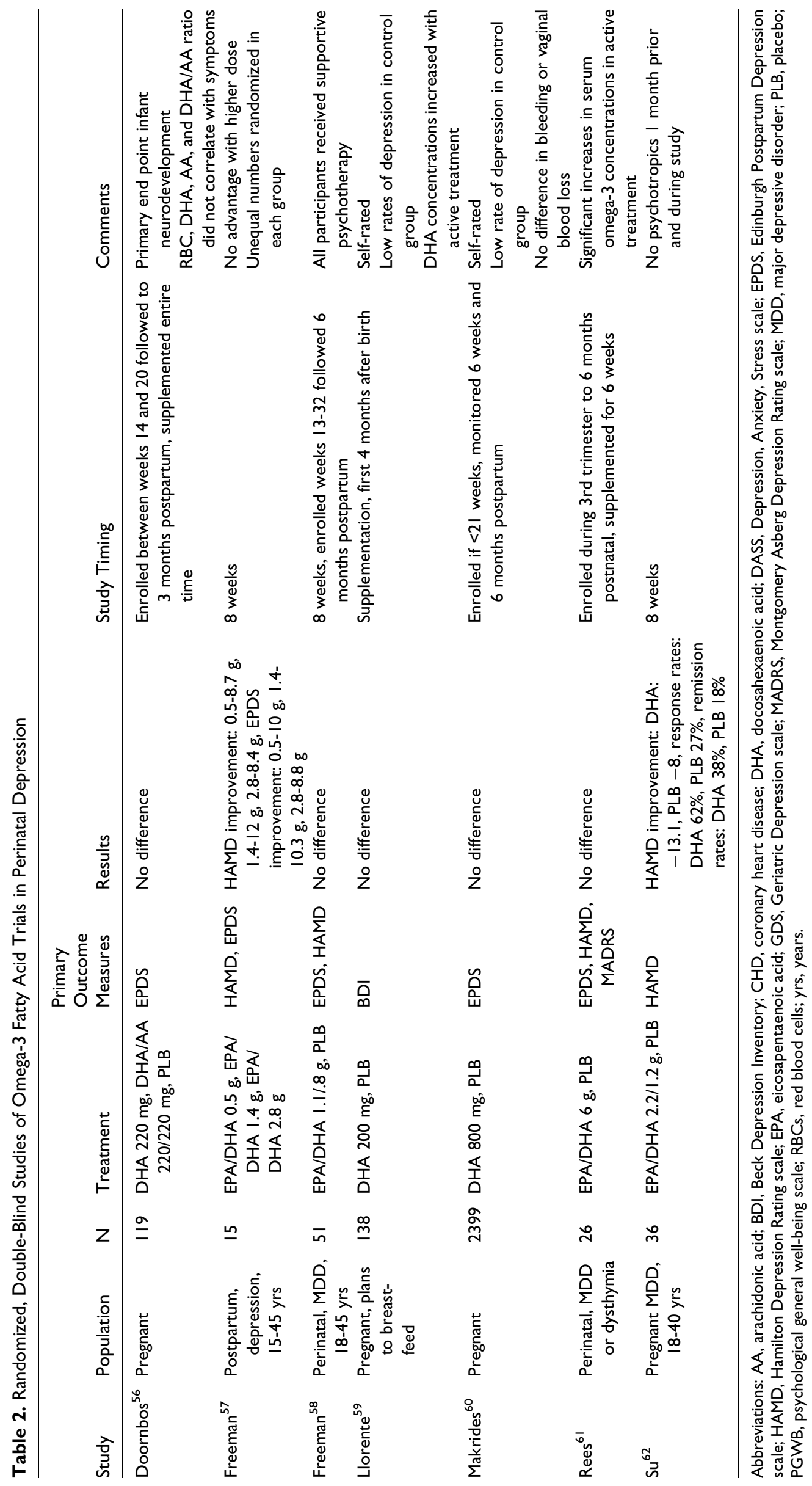




\section{Bipolar Disorder}

Abnormalities in the omega- 6 fatty acid, AA, are thought to play a role in the pathogenesis of bipolar disorder. ${ }^{63,64}$ This has been demonstrated in several studies finding products of AA are increased in the blood, saliva, and cerebrospinal fluid of patients with bipolar disorder. ${ }^{63}$ While omega-3 and omega- 6 fatty acids both increase the proinflammatory eicosanoids, those derived from omega- 6 fatty acids result in more inflammation than those derived from omega-3 fatty acids. So, in people with high omega-6:omega- 3 fatty acid ratios, one would expect increased inflammation and possibly increased neuronal cell death. ${ }^{63,64}$ Ideally, a shift in dietary intake to increased omega-3 fatty acids would decrease inflammation associated with omega-6 fatty acids.

This is supported by commonly used treatments for bipolar disorder which have a similar effect as omega- 6 and omega-3 fatty acids (eg, lithium, carbamazepine, and valproate). In animal models it has been found that these medications decrease the turnover of the omega- 6 fatty acid, AA, and may improve symptoms of bipolar disorder through secondary decreases in proinflammatory by-products of AA. ${ }^{63,64}$

Epidemiologic studies also support the link of omega6:omega-3 fatty acid ratios in bipolar disorder. In one crossnational study, seafood consumption was inversely related to rates of bipolar I, bipolar II, and bipolar spectrum disorders. ${ }^{65}$ The relationship seemed strongest with bipolar II disorder. The authors reported a minimum consumption of 50 pounds of fish per year, which they estimate is equal to $3 \mathrm{~g}$ of EPA/DHA daily, was associated with decreased rates of bipolar disorders. Some studies have reported lower concentrations of omega-3 fatty acids in patients being treated for bipolar disorder, although other studies have not replicated these findings. ${ }^{66-68}$ Clayton et al found no differences in omega-3 fatty acid concentrations in pediatric bipolar disorder when controlling for the intake of omega- 3 fatty acids. ${ }^{69}$ Rather, the authors suggest that the high cost of fresh fish and low socioeconomic status often associated with bipolar disorder may account for the lower concentrations of omega-3 fatty.

Omega-3 fatty acid concentrations have been correlated with symptom severity in bipolar disorder. Clayton reported that in pediatric bipolar disorder, DHA concentrations were associated with depression severity; while EPA concentrations were more closely associated with manic symptoms. ${ }^{70}$ These results were replicated in a study of adults with bipolar disorder that reported omega-3 fatty acid concentrations and omega-6:omega-3 ratio were associated with severity of manic symptoms. ${ }^{71}$

Three open-label trials have found adjunctive omega-3 fatty acid supplementation to be effective in bipolar disorder (Table 3). ${ }^{72-80}$ The two studies in pediatric patients with bipolar disorder both reported improvement in manic symptoms, one of which reported improvements in depression when omega-3 fatty acids were added to ongoing treatment. ${ }^{70,79}$ The one open-label adult trial reported significant improvement in depressive symptoms when omega-3 fatty acids were added to ongoing treatment. ${ }^{75}$
Results from more rigorous studies have been mixed (Table 3 ). Three RCTs reported no benefit, while 2 reported improvements with omega-3 fatty acid augmentation in adults with bipolar disorder. $^{72-74,76,77}$ Two negative trials studied omega-3 fatty acid supplementation in subpopulations (acute mania, women discontinuing mood stabilizers prior to becoming pregnant), making it difficult to generalize the findings. ${ }^{72,76}$ Both positive trials reported significant improvement in depressive symptoms but no benefit for mania, suggesting omega-3 fatty acids may play a limited role in adult bipolar disorder. ${ }^{73,77}$

The one randomized controlled trial on pediatric bipolar disorder reported no benefit with ALA supplementation. However, overall illness and manic symptoms improved in patients with significant increases in EPA concentrations. ${ }^{78}$

Given the disparity in methods, populations studied, and outcomes, it is difficult to draw any firm conclusions about the relationship of omega-6:omega-3 fatty acids and bipolar disorder. While epidemiologic data indicate that there is a relationship, other studies controlling for omega-3 fatty acid intake do not find a similar association. In positive studies, data indicate either 2 to $4 \mathrm{~g}$ daily intake of EPA alone or in combination with DHA are beneficial in adults in the depressive phase of the illness.

\section{Schizophrenia}

Alterations in neuronal membranes and fatty acid metabolism have been implicated in the pathogenesis of schizophrenia. ${ }^{80,81}$ Omega-3 fatty acids are known to effect membrane fluidity, dopaminergic and serotonergic systems, and modulate AA release, all of which are proposed to be altered in patients with schizophrenia. In addition, through modulation of glutathione, omega-3 fatty acids are also thought to be involved in neuronal protection from excitotoxic and oxidative stress. ${ }^{82-85}$

Such theorized deficiencies have been supported by clinical data. Deficiencies in AA, an omega-6 fatty acid, and the omega-3 fatty acids such as EPA and DHA have been reported in drug-naive and medicated patients with schizophrenia when compared with matched controls and patients with bipolar disorder. $^{86-88}$ Patients with schizophrenia and tardive dyskinesia have also been shown to have decreased concentrations of erythrocyte omega- 6 fatty acids. ${ }^{89}$

These findings are supported by studies which report that lowered dietary intake of fatty acids is associated with psychotic symptoms and the course of schizophrenia. ${ }^{90,91}$ One study of 33000 women with a low intake of omega-3 fatty acids were found to have an increased risk of psychotic symptoms. ${ }^{92}$ Another study reported significant deficiencies in a woman's diet during pregnancy may increase the risk of schizophrenia in her children.93 Omega-3 fatty acid supplementation may prevent or delay the onset of schizophrenia (Table 4). ${ }^{94,95}$ In patients at high risk of psychosis, Amminger and colleagues reported $4.9 \%$ of EPA/DHA-treated patients and $27.5 \%$ of placebo-treated patients developed psychotic symptoms during 40 weeks. ${ }^{94}$ Peet reported $57 \%$ and $100 \%$ of EPA- and 


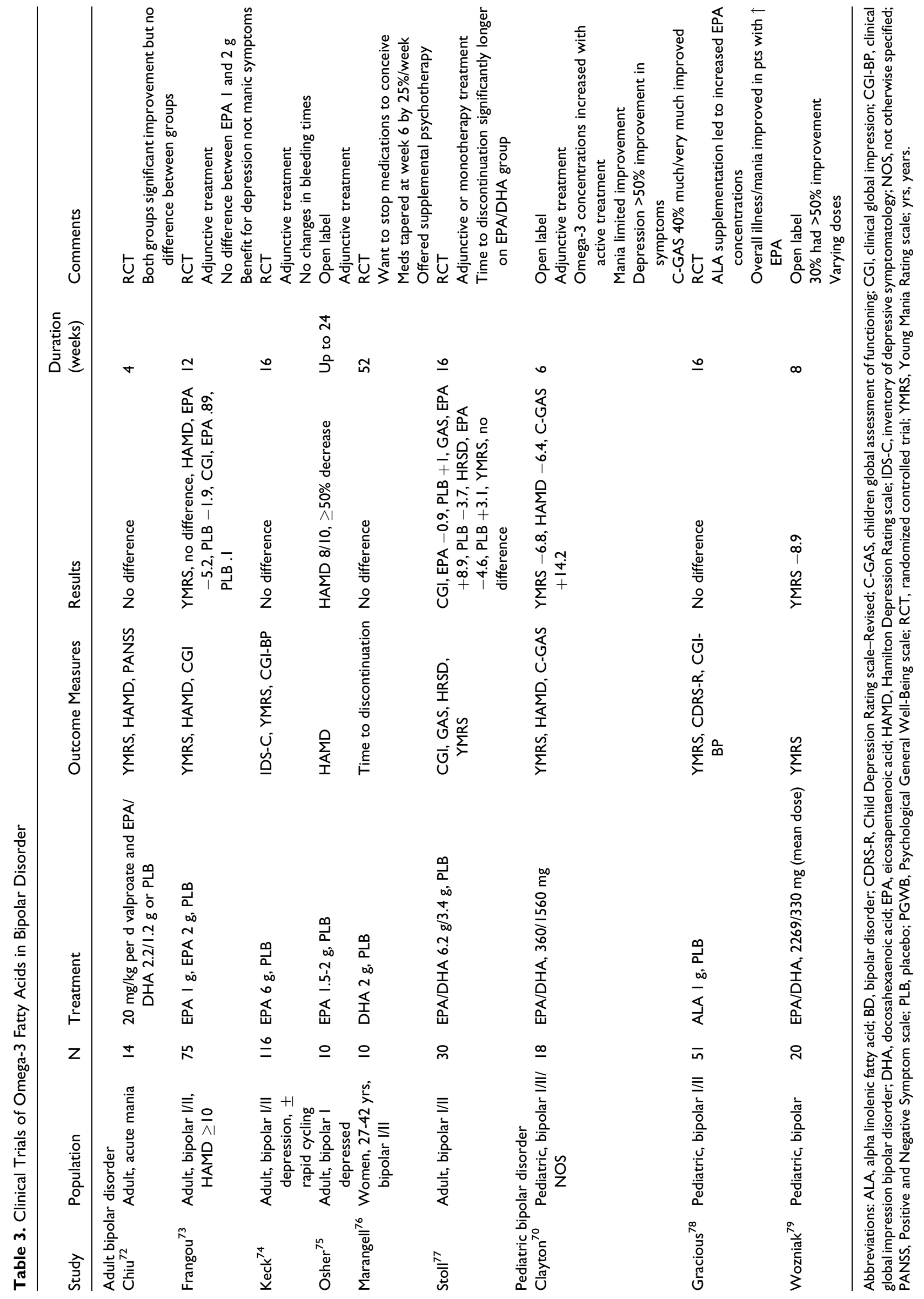




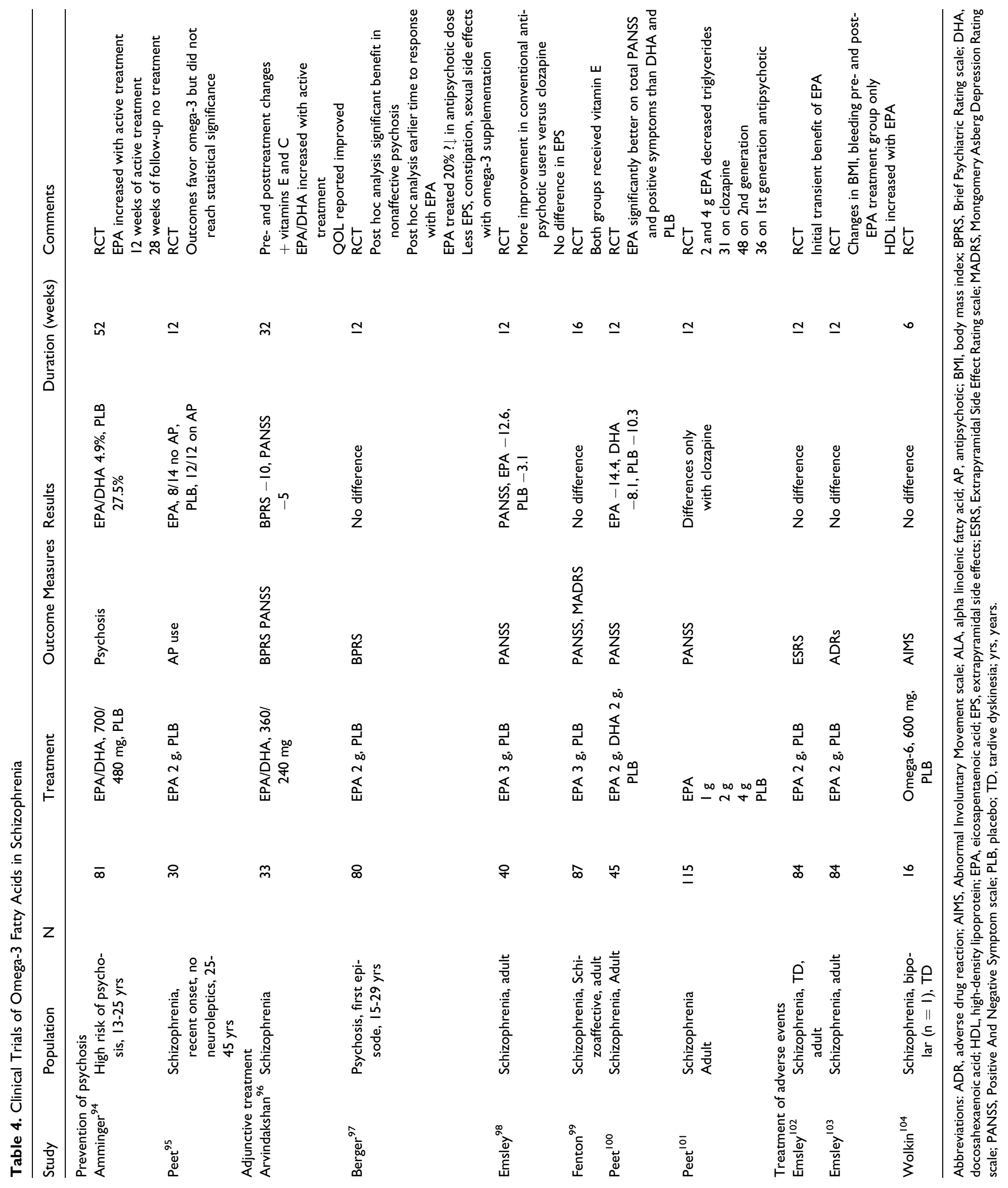


placebo-treated patients required an antipsychotic at the end of 12 weeks. $^{95}$

Six studies have been reported assessing the role of adjunctive omega-3 fatty acids for the treatment of psychosis (Table 4). ${ }^{96-101}$ One open-label study reported significant improvements in general psychopathology with omega-3 fatty acid supplementation. ${ }^{96}$ Of the 5 RCTs, 2 were negative, ${ }^{97,99} 2$ were positive, ${ }^{98,100}$ and 1 found benefits only when omega-3 fatty acids were added to clozapine. ${ }^{101}$ Post hoc analyses of one of the negative studies did report omega-3 supplementation was beneficial in nonaffective psychosis and associated with a $20 \%$ decrease in total antipsychotic dose. ${ }^{97}$ Other studies report differential effects by concomitant antipsychotics with one reporting benefit only in patients treated with clozapine and another reporting increased benefits in augmentation of conventional antipsychotics. ${ }^{98,101}$ The one study of both EPA and DHA found EPA significantly better than DHA. ${ }^{100}$

The role of omega- 3 and omega- 6 fatty acid supplementation on side effects in patients with schizophrenia has been assessed in 3 RCTs. ${ }^{102-104}$ These trials found no difference in side effects, extrapyramidal side effects, and tardive dyskinesia with active treatment and placebo. However, all of these trials were small and of short duration. Emsley et al did find increased bleeding time, body mass index, and decreased high-density lipoprotein (HDL) concentrations in patients preand post-EPA supplementation. ${ }^{103}$

Studies assessing prevention of psychosis with omega-3 fatty acid supplementation are promising. Although far from conclusive, data suggest omega-3 fatty acids are more beneficial for nonaffective psychoses. Studies of omega-3 fatty acid treatment of schizophrenia are mixed. Data suggest EPA is more effective than DHA monotherapy. Given the cardiovascular benefits and limited side effects of omega-3 fatty acids when compared to antipsychotics, supplementation with EPA or EPA/DHA combination in 1 to $2 \mathrm{~g}$ daily is reasonable for the prevention and adjunctive treatment of psychosis. However, caution should be used in patients at risk of bleeding.

\section{Attention-Deficit Hyperactivity Disorder}

In the brain, the principle fatty acid is DHA which increases in the frontal cortex during childhood and adolescence. ${ }^{105}$ This deposition of DHA is associated with neurocognitive maturation. ${ }^{105,106}$ Disruption in the DHA accumulation in the maturing brain can lead to cognitive and physical problems. ${ }^{105,106}$ It has been postulated that altered fatty acid concentrations are associated with symptoms of attention-deficit hyperactivity disorder (ADHD). ${ }^{107}$ Most, but not all studies, report lower concentrations of omega- 6 fatty acids, DHA and EPA, and higher omega-6:omega-3 fatty acid ratio in children with ADHD. ${ }^{107}$ In addition, low concentrations of omega-3 fatty acids have been observed in the plasma phospholipids and erythrocytes of subjects with ADHD. ${ }^{108}$ In children, studies indicate alterations of omega-3 fatty acids are related to cognitive problems of ADHD, while changes in omega- 6 fatty acids are associated with physical deficits. ${ }^{109,110}$ This is supported by one functional magnetic resonance imaging study reporting DHA supplementation increased prefrontal cortex activation during sustained attention in healthy boys. ${ }^{105}$ Symptom severity may be related to omega-3 plasma concentrations in children. ${ }^{110}$ Although, one study in adults failed to find an association of omega-3 fatty acid concentrations in adults with ADHD. ${ }^{111}$

All placebo-controlled studies are in pediatric ADHD (Table 5). ${ }^{112-125}$ Few report significant improvements in primary outcome measures with active treatment. Half of the trials failed to find a significant benefit with omega-3 supplementation, while others found benefits in subpopulations, mildly ill children, or for limited symptoms only. ${ }^{12,116,117,120,121,123,125}$ There were no differences between groups in trials that distinguished between inattentive and hyperactive types. Several of the trials were for disorders related to ADHD. Many studies were limited by small sample size, making interpretation of negative findings difficult. Of the studies with positive findings, most reported benefit for inattention only. ${ }^{114,121,122}$

Current evidence does not support a role of omega-3 fatty acids in the treatment of ADHD. However, many studies were limited by small sample size or populations without a clear diagnosis of ADHD. Though, generally well tolerated, routine recommendation of omega-3 fatty acids for the treatment of pediatric ADHD is premature. Given the lack of studies in adults, omega-3 fatty acids should not be recommended for the treatment of adult ADHD.

\section{Autism Spectrum Disorders}

The term autism spectrum disorder (ASD) encompasses a range of neurodevelopmental disorders, all of which involve impairment in social interaction, struggles with verbal and nonverbal communication, and stereotyped, repetitive behavioral patterns. ${ }^{126}$ Classical ASD, or autistic disorder, is diagnosed when these symptoms manifest in their most severe form. Currently, Asperger's disorder has distinct Diagnostic and Statistical Manual of Mental Disorders (Fourth Edition [DSM-IV]) criteria, with the most notable difference being the absence of a delay in communicative abilities. ${ }^{127}$ Individuals with ASD characteristics who do not identify with either of 2 subcategories are typically given a diagnosis of pervasive developmental disorder, not otherwise specified (PDD-NOS). ${ }^{128}$ Although the average age of diagnosis is 3 years, marked behavioral disparities have been observed in children younger than 12 months. ${ }^{129,130}$

The proposed etiologies of ASDs cover a broad range, including abnormalities in metabolism, inflammatory markers, genetics, neurotransmitter systems, and oxidative stress. ${ }^{131-133}$ For instance, it has been suggested that inflammation and apoptosis play a significant role in autism, ${ }^{133,134}$ while omega-3 fatty acids have been shown to prevent neuronal apoptosis ${ }^{135,136}$ and influence neuroinflammation. ${ }^{136}$ Functional polymorphisms in serotonin (5-HT) and dopamine (DA) transporters have been noted in autism, ${ }^{137}$ while omega- 3 fatty acids have been shown to affect 5-HT and DA neurotransmitter 


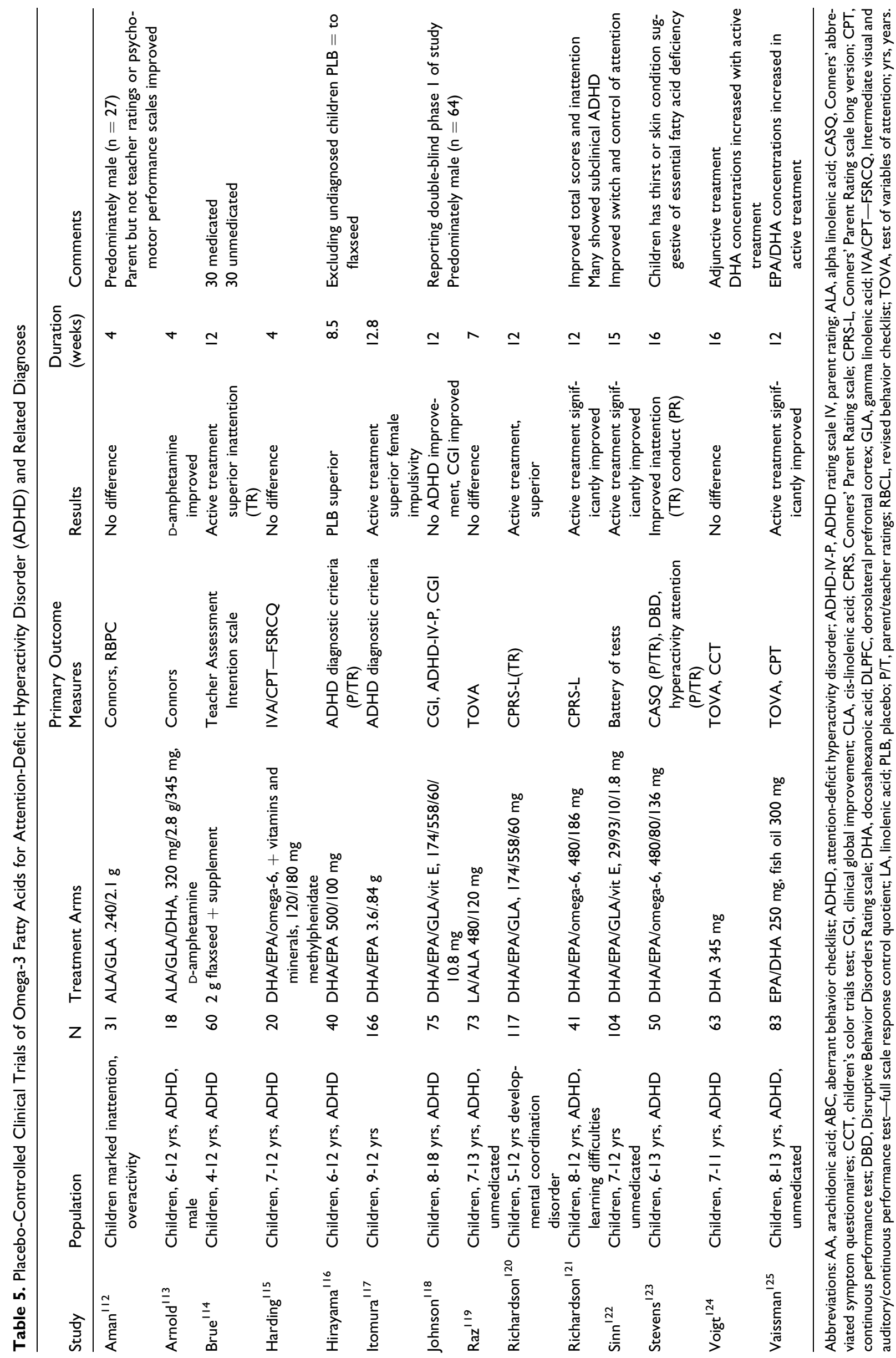


systems. ${ }^{137,138}$ Fatty acids have wide implications in brain development and subsequent behavior, including the ability to respond to external stimuli, while abnormal responses to environmental stimulation are characteristic of autism. ${ }^{139,140}$ In addition, low concentrations of omega- 3 fatty acids have been observed in the plasma phospholipids and erythrocytes of subjects with ADHD, ${ }^{108}$ a neurodevelopmental disorder with clinical presentation and genetic biomarkers comparable to that of autism. ${ }^{141-143}$

Children with autism have been shown to have $20 \%$ lower omega-3 fatty acid plasma concentrations compared with mentally retarded controls. ${ }^{144}$ The same trial reported no significant difference in the omega-6 fatty acid concentrations, which resulted in a significant increase in the omega-6:omega-3 ratio in the group with autism. Sliwinski et al analyzed plasma samples from high-functioning adolescent males and a healthy control group. ${ }^{145}$ They discovered a statistically significant increase in plasma DHA, total omega-3 fatty acids, and the omega-6/omega-3 ratio in the autistic subjects. Wiest et al reported differences in omega-3 fatty acid concentrations were not significant when accounting for dietary intake. ${ }^{144}$

Risperidone, a common drug therapy in ASD, may influence fatty acid profiles as well. Studies have demonstrated that chronic therapy with risperidone normalizes inflammatory biomarkers, significantly affects ALA-DHA biosynthesis, and increases omega-3 composition of peripheral and central membranes in rats with omega-3 fatty acid deficiency. ${ }^{146,147}$ Risperidone also appears to have a wider range of symptom improvement, including aggressiveness, hyperactivity, irritability, stereotypy, social withdrawal, and lack of interests, as compared to omega-3 fatty acids which only specifically improve hyperactivity. ${ }^{148}$

Two trials analyzed fatty acid compositions of red blood cells rather than plasma concentrations. Bell et al had positive findings, demonstrating that subjects with autism had significantly elevated concentrations of EPA and DHA and significantly reduced concentrations of AA. ${ }^{149}$ They observed significantly higher percentages of omega- 6 fatty acids and total saturates in the red blood cell membranes of subjects with regressive autism in particular, when compared to controls. $\mathrm{Bu}$ et al also encountered notable differences in omega- 6 fatty acid profiles between children with clinical regression autism and those with early onset autism. ${ }^{150}$ These findings indicate a potential differential etiology between classical, typical onset, autism and regressive autism, which develop after initial child development.

A collection of open-label pilot studies came to disparate conclusions. Johnson et al did not observe any clinical gains in autistic children given omega-3 supplements. ${ }^{151}$ Politi et al did not observe any statistically significant improvements in autistic adults after omega- 3 treatment, utilizing the Rossago Behavioral Checklist. ${ }^{152}$ However, the problematic behaviors addressed by this instrument are only a portion of autism's symptomatic picture. In contrast, Meiri et al observed a statistically significant improvement in subjects treated with omega3 fatty acids. ${ }^{153}$ Meguid et al also observed positive results in autistic children administered with a preparation of both omega-3 and omega- 6 fatty acids. ${ }^{154}$ Beneficial effects of omega-3 supplementation in children were also demonstrated in an open-label trial by Patrick and Salik, who specifically looked at language and learning skills. ${ }^{155}$

RCTs investigating the effects of omega-3 fatty acid treatment in autism are limited (Table 6). ${ }^{151-157}$ One RCT reported no significant difference between autistic subjects treated with omega-3 fatty acids as compared to placebo. ${ }^{156}$ However, there were nonsignificant reductions in hyperactivity and stereotypy subscales. Another randomized control trial noted improvements, including nonsignificant decreases in hyperactivity, with omega- 3 treatment. ${ }^{158}$ This trial was unique in that it analyzed cytokines as a biomarker of anti-inflammation effects of omega-3 treatment. Surprisingly, there was a statistically significant increase in the tumor necrosis factor- $\alpha$ (TNF- $\alpha$ ) plasma concentrations in the treatment group as compared to placebo. One cytokine, interleukin 2 (IL-2), demonstrated a negative correlation with hyperactivity.

In summary, 4 of the 7 clinical trials demonstrated statistically significant changes. The lack of positive findings in the remaining trials is inadequate to fully discredit omega-3 fatty acids' potential benefit in improving symptoms of autism. Nonsignificant conclusions could be attributed to insufficient omega-3 dosing or improper EPA/DHA ratios. In addition, variability in results could be attributed to the presence or absence of vitamin $\mathrm{E}$, which some trials included in their treatment arm to avoid lipid peroxidation. It is plausible that the treatment durations were too brief to allow substantial improvements to take place. However, Meiri et al declared that most of the improvements they observed occurred within the first 6 weeks, although raw data for this were not reported. ${ }^{153}$

Several drug classes are typically used to manage some behavioral manifestations of autism, including antipsychotics, psychostimulants, antiepileptics, and antidepressants. Unfortunately, the side effects of these medications are often a limiting factor. ${ }^{158}$ More trials are warranted, particularly in adult populations, before an unequivocal conclusion can be made regarding omega-3's role in therapy. However, as omega-3 fatty acids are fairly innocuous, inexpensive, and readily available, a trial of omega-3 fatty acids in autistic children may be appropriate. Combinations of EPA and DHA showed the greatest benefit. Unfortunately, there is insufficient evidence to define a single most-effective dose or ratio. Children tolerated doses as high as $840 \mathrm{mg}$ EPA and $700 \mathrm{mg}$ DHA. However, trials administering doses as low as $52 \mathrm{mg}$ EPA and $90 \mathrm{mg}$ DHA yielded positive results. These particular trials also administered vitamin $\mathrm{E}$ (5 or $10 \mathrm{mg} / \mathrm{d}$ ), which suggests a dose-sparing effect. ${ }^{155,156}$ There is evidence for EPA/DHA ratios between 1.5:1 and $2: 1$, although this is from only 2 trials. ${ }^{154,156}$ Those considering a trial treatment with omega-3 fatty acids should consult a health care practitioner prior to initiating therapy, as the FDA has not approved the use of fish oil supplements in children ( $<18$ years). Omega-3 fatty acids' inhibition of platelet aggregation warrants precaution in those at an increased risk of bleeding or being treated with anticoagulants. ${ }^{157}$ 


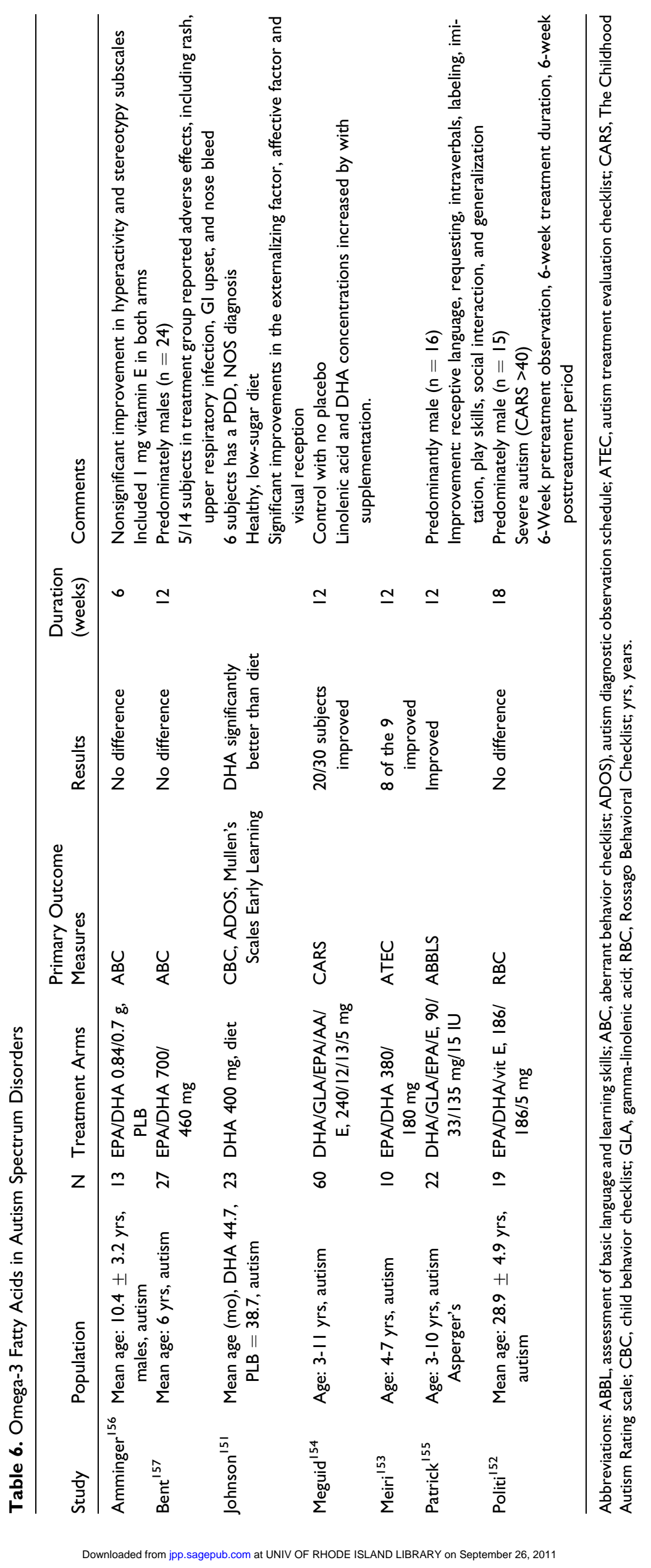




\section{Anxiety Disorders}

There are limited studies of omega-3 fatty acid supplementation in anxiety disorders. Many of the studies address only a select population. In terms of active treatment, a study of 126 university students with significant test anxiety reported 3 weeks of omega-3/omega-6 supplementation was associated with improved appetite, mood, organization, and concentration compared with placebo. ${ }^{159}$ The authors also reported a significant decrease in salivary cortisol with active treatment. This finding should be interpreted with caution since the placebotreated students had nonsignificant decreases in salivary cortisol as well.

Compared with placebo, anger and anxiety have also been reported to decrease with omega- 3 fatty acid supplementation in men with substance abuse. ${ }^{160}$ Researchers found 3 months of EPA/DHA supplementation decreased the anxiety scores in patients with substance abuse compared with placebo. The differences in anxiety symptoms remained significant for 3 months following the discontinuation of the supplements.

Studies of omega-3 fatty acids in obsessive compulsive disorder are limited. Fux and colleagues reported EPA supplementation was ineffective for the treatment of obsessive compulsive disorder. ${ }^{161}$

Results regarding omega-3 fatty acid supplementation in posttraumatic stress disorder (PTSD) are conflicting. One study was terminated early when $2 \mathrm{~g}$ daily intake of EPA was found to worsen symptoms in 5 of 6 patients. ${ }^{162}$ However, Matsuoka et al reported open-label treatment with omega-3 fatty acids could decrease the risk of subsequent PTSD in patients with accidental injuries. ${ }^{163}$

Data are too limited to assess the efficacy of omega-3 fatty acids in the treatment of anxiety disorders. While they may be beneficial in those with comorbid mood and anxiety disorders, omega-3 fatty acids should not be routinely used for patients with PTSD.

\section{Other Disorders}

Omega-3 fatty acids have been explored in a limited fashion in many disorders including substance abuse and borderline personality disorder. However, there are insufficient data to draw any conclusions about the effectiveness of omega- 3 fatty acids in these disorders. Omega-3 fatty acids have been studied extensively in cognition, cognitive decline, dementia, Alzheimer's disease, and cognitive symptoms associated with other disorders. This is beyond the scope of this review.

\section{Safety of Omega-3 Fatty Acids}

Clinical trials demonstrate the risk of serious adverse events with omega- 3 fatty acids are comparable with placebo. The most common side effects reported were gastrointestinal (diarrhea and belching). The FDA has recognized intakes up to $3 \mathrm{~g} / \mathrm{d}$ of omega-3 fatty acids are safe. ${ }^{19}$ The FDA has also recognized and approved qualified health claims for EPA and DHA. ${ }^{19}$ One study did report an increase in bleeding time after EPA supplementation, but this increase did not result in clinical side effects. ${ }^{90}$ However, other studies report no changes in bleeding time. ${ }^{75}$ In one large study of pregnant women there was no increase in the rate of bleeding with omega-3 fatty acid supplementation. ${ }^{60}$ In fact, the study found decreased rates of preterm labor with omega-3 fatty acid supplementation.

While fish may be contaminated with heavy metals, omega3 fatty acid supplements usually contain very limited quantities of organochloride contaminants and no methylmercury. ${ }^{168}$ However, significant levels of contaminants have been reported with some supplements. ${ }^{163,164}$ While omega-3 fatty acid purification processes substantially decrease the risk of environmental contamination, krill oil can be used as an alternate source of marine-derived fish oils for those who remain concerned. ${ }^{165}$ For those wishing to increase omega-3 fatty acid intake through fish consumption, the FDA recommends avoiding fish high in methylmercury such as shark, swordfish, king mackerel, or tilefish. ${ }^{166}$ Instead consider recommending fish low in methylmercury content such as shrimp, canned light tuna, salmon, pollock, and catfish. ${ }^{166}$

\section{Conclusions}

Omega-3 fatty acids have been studied in numerous disease states. They have cardioprotective effects and are relatively safe and inexpensive. In general, omega-3 fatty acids were well tolerated by many groups including pediatric and geriatric populations. While safe when taken in usual daily doses, caution should be used with large doses in patients at risk of bleeding abnormalities. Beyond that caution, side effects of fatty acids appear to be mild and primarily involve the gastrointestinal tract (ie, nausea, diarrhea, and belching).

The bulk of the data support omega-3 fatty acids' role in the treatment of mood disorders. While data are promising for psychiatric illness beyond affective disorders, it is premature to routinely recommend omega- 3 fatty acids as the primary treatment for most other psychiatric disorders. However, given the favorable side effect profile and cardiovascular benefits of omega-3 fatty acids, they would appear to be safe for most populations.

\section{Declaration of Conflicting Interests}

The author(s) declared no potential conflicts of interest with respect to the research, authorship, and/or publication of this article.

\section{Funding}

The author(s) received no financial support for the research, authorship, and/or publication of this article.

\section{References}

1. Calder PC, Yaqoob PY. Understanding omega-3 polyunsaturated fatty acids. Postgrad Med. 2009;121(6):148-157.

2. Kidd PM. Omega-3 DHA and EPA for cognitive, behavior, and mood: clinical findings and structural functional synergies with cell membrane phospholipids. Alt Med Rev. 2007;12(3):207-227. 
3. Heinrichs SC. Dietary omega-3 fatty acid supplementation for optimizing neuronal structure. Mol Nutr Food Res. 2010;54:447-456.

4. Marcheselli VL, Hong S, Lukiw WJ, et al. Novel docosanoids inhibit brain ischemia-reperfusion-mediated leukocyte infiltration and pro-inflammatory gene expression. J Biol Chem. 2003;278(44): 43807-43817.

5. Serhan CN, Hong S, Gronert K, et al. Resolvins: a family of bioactive products of omega-3 fatty acid transformation circuits initiated by aspirin treatment that counter proinflammation signals. J Exp Med. 2002;196(8):1025-1037.

6. Hong S, Gronert K, Devchand PR, et al. Novel docosatrienes and 17S-resolvins generated from docosahexaenoic acid in murine brain, human blood, and glial cells. Autacoids in antiinflammation. J Biol Chem. 2003;278(17):14677-14687.

7. Cade J, Thomas E, Vail A. Case-control study of breast cancer in south east England: nutritional factors. J Epidemiol Comm Health. 1998;52(2):105-110.

8. Lauritzen L, Hansen HS, Jorgensen MH, et al. The essentiality of long chain n-3 fatty acids in relation to development and function of the brain and retina. Prog Lipid Res. 2001;40(12):1-94.

9. Niu SL, Mitchell DC, Lim SY, et al. Reduced G protein-coupled signaling efficiency in retinal rod outer segments in response to n-3 fatty acid deficiency. J Biol Chem. 2004;279(30):31098-31104.

10. Hirashima F, Parow AM, Stoll AL, et al. Omega-3 fatty acid treatment and T2 whole brain relaxation times in bipolar disorder. $\mathrm{Am}$ J Psychiatry. 2004;161:1922-1924.

11. McVeigh GE, Brennan, Cohn JN, et al. N-3 fatty acids and urinary excretion of nitric oxide metabolites in humans. Am J Clin Nutr. 1997;65:459-464.

12. Chin JP, Dart AM. How do fish oils affect vascular function? Clin Exp Pharmacol Physiol. 1995;22:71-81.

13. TEritslad J, Arnesen H, Gronseth K, et al. Effect of dietary supplementation with n-3 fatty acids on coronary artery bypass graft patency. Am J Cardiol. 1996;77:31-36.

14. Abe Y, El-Masri B, Kimball KT, et al. Soluble cell adhesion molecules in hypertriglyceridemia and potential significance on monocyte adhesion. Arteroiscler Thromb Vasc Biol. 1998;18: 723-731.

15. Kang JX, Leaf A. Antiarrythmic effects of polyunsaturated fatty acids: recent studies. Circulation. 1996;94:1774-1780.

16. Kris-Etherton PM, Harris WS, Appel LJ, for the nutrition committee. AHA scientific statement on fish consumption, fish oil, omega-3 fatty acids, and cardiovascular disease. Circulation. 2002;106:2747-2757.

17. Holub DJ, Holub BJ. Omega-3 fatty acids from fish oils and cardiovascular disease. Mol Cell Biochem. 2004;263:217-225.

18. Office of Nutritional Products, Labeling, and Dietary Supplements, Center for Food Safety and Applied Nutrition, US Food and Drug Administration. Letter responding to a request to reconsider the qualified health claim for a dietary supplement health clain for omega-3 fatty acids and coronary heart disease. http://www.fda.gov/SiteIndex/ucm072932.htm. Accessed June 21, 2011.

19. Freeman MP, Hibbeln JR, Wisner KL, et al. Omega-3 fatty acids: evidence basis for treatment and future research in psychiatry. J Clin Psychiatry. 2006;67:1954-1967.
20. Timonen M, Horrobin D, Jokelainen J, et al. Fish consumption and depression: the northern Finland 1996 birth cohort. J Affect Disord. 2004;82:447-452.

21. Lin PY, Huang SY, Su KP. A meta-analytic review of polyunsaturated fatty acid compositions in patients with depression. Biol Psychiatry. 2010;68:140-147.

22. Tiemeier H, van Tuijil HR, Kiliaan AJ, et al. Plasma fatty acid composition and depression are associated in the elderly: the Rotterdam study. Am J Clin Nutr. 2003;78:40-46.

23. Sublette ME, Segal-Isaacson CJ, Cooper TB, et al. Omega-3 polyunsaturated essential fatty acid status as a predictor of future suicide risk. Am J Psychiatry. 2006;163(6):1100-1102.

24. Tanskanen A, Hibbeln JR, Tuomilehto J, et al. Fish consumption and depressive symptoms in the general population in Finland. Psychiatr Serv. 2001;52:529-531.

25. Maes M, Smith R, Christophe A, et al. Fatty acid composition in major depression: decreased omega-3 fractions in cholesteryl esters and increased C20:4 omega-6/C20:5 omega-3 ration in cholesteryl esters and phospholipids. J Affect Disord. 1996; 38:35-46

26. Adams PB, Lawson S, Sanigorski A, et al. Arachidonic acid to eisocapentaenoic acid correlates positively with clinical symptoms of depression. Lipids. 1996;(suppl):S157-S161.

27. Peet M, Murphy B, Shay J, et al. Depletion of omega-3 fatty acid levels in red blood cell membranes of depressive patients. Biol Psychiatry. 1998;43:315-319.

28. Murakami K, Miyake Y, Sasaki S, et al. Fish and n-3 polyunsaturated fatty acid intake and depressive symptoms: Ryukyus child health study. Pediatrics. 2010;126(3):e623-e630.

29. Hakkarainen R, Partonen T, Haukka J, et al. Is low dietary intake of omega-3 fatty acids associated with depression? Am J Psychiatry. 2004;161:567-569.

30. Bot A, Pouwer F, Assies J, et al. Eicosapentaenoic acid as an add on to antidepressant medication for comorbid major depression in patients with diabetes mellitus: a randomized, double blind, placebo controlled study. J Affect Disord. 2010;126:282-286.

31. Carney RM, Freedland KE, Rubin EH, et al. Omega-3 augmentation of sertraline in treatment of depression in patients with coronary heart disease: a randomized controlled trial. JAMA. 2009;302(15):1651-1657.

32. Grenyer BF, Crowe T, Owen AJ, et al. Fish oil supplementation in the treatment of major depression: a randomized double blind placebo controlled trial. Prog Neuropsychopharmacol Biol Psychiatry. 2007;31(7):1393-1396.

33. Nemets B, Stahl Z, Belmaker RH. Addition of omega-3 fatty acid to maintenance medication treatment for recurrent unipolar depression. Am J Psychiatry. 2002;159(3):477-479.

34. Peet M, Horrobin DF. A dose ranging study of the effects of ethyleicosapentaenoate in patients with ongoing depression despite apparently adequate treatment with standard drugs. Arch Gen Psychiatry. 2002;59(10):913-919.

35. Silvers KM, Woolley CC, Hamilton FC, et al. Randomized double blind placebo controlled trial of fish oil in the treatment of depression. Prostaglandins Leukot Essent Fatty Acids. 2005;72(3):211-218.

36. Su KP, Huang SY, Chiu CC, et al. Omega-3 fatty acids in major depressive disorder: a preliminary double blind, placebo 
controlled trial. Eur Neuropsychopharmacol. 2003;13(4): 267-271.

37. Nemets H, Nemets B, Apter A, et al. Omega-3 treatment of childhood depression: a controlled double blind pilot study. Am J Psychiatry. 2006;163(6):1098-1100.

38. Jazayeri S, Tehrani-Doost M, Keshavarz SA, et al. Comparison of therapeutic effects of omega-3 fatty acid eicosapentaenoic acid and fluoxetine, separately and in combination in major depressive disorder. Aust N Z J Psychiatry. 2008;42(3):192-198.

39. Lucas M, Asselin G, Merette C, et al. Ethyl-eicosapentaenoic acid for the treatment of psychological distress and depressive symptoms in middle-aged women: a double blind placebo controlled randomized trial. Am J Clin Nutr. 2009;89(2):641-651.

40. Marangell LB, Martinez JM, Zboyan HA, et al. A double blind placebo controlled study of the omega- 3 fatty acid docosahexaenoic acid in the treatment of major depression. Am J Psychiatry. 2003;160:996-998.

41. Mischoulon D, Papakostas GI, Dording CM, et al. A double blind randomized controlled trial of ethyl-eicosapentaenoate for major depression. J Clin Psychiatry. 2009;70(12):1363-1644.

42. Mischoulon D, Best-Popescu C, Laposata M, et al. A double blind dose finding pilot study of docosahexaenoic acid (DHA) for major depressive disorder. Eur Neuropsychopharmacol. 2008;18(9): 639-645.

43. Rogers PJ, Appleton KM, Kessler D, et al. No effect of n-3 long chain polyunsaturated fatty acid (EPA and DHA) supplementation on depressed mood and cognitive function: a randomized controlled trial. Br J Nutr. 2008;99:421-431.

44. Rondanelli M, Giacosa A, Opizzi A, et al. Effects of omega-3 fatty acids supplementation on depressive symptoms and on health related quality of life in treatment of elderly women with depression: a double blind placebo controlled randomized trial. J Am Coll Nutr. 2010;29(1):55-64.

45. van de Rest O, Geleijnse JM, Kok FJ, et al. Effect of fish oil supplementation on mental well being in older subjects: a randomized double blind placebo controlled trial. Am J Clin Nutr. 2008;88:706-713.

46. Martin JG. EPA but not DHA appears responsible to for the efficacy of omega-3 long chain polyunsaturated fatty acid supplementation in depression: evidence from a meta analysis of randomized controlled trials. J Am Coll Nutr. 2009;28(5):525-542.

47. Innis SM. Perinatal biochemistry and physiology of long chain polyunsaturated fats. Pediatrics. 2003;143(4 suppl):S1-S8.

48. Hibbeln JR, Davis JM. Considerations regarding neuropsychiatric nutritional requirements for intakes of omega-3 highly unsaturated fatty acids. Prostaglandins Leukot Essent Fatty Acids. 2009;81:179-186.

49. Hibbeln JR. Seafood consumption, the DHA content of mothers' milk and prevalence rates of postpartum depression. $J$ Affect Disord. 2002;69:15-29.

50. Sontrop J, Campbell MK. Omega-3 polyunsaturated fatty acids and depression: a review of the evidence and methodological critique. Prev Med. 2006;42:4-13.

51. Brown JC, Scott KM, Silvers KM. Fish consumption and omega-3 status after birth are not associated with post natal depression. $J$ Affect Disord. 2006;90(2-3):1310139.
52. Miyake Y, Sasaki S, Yokoyama T, et al. Risk of postpartum depression in relation to dietary fish intake and fat intake in Japan: the Osaka maternal and child health study. Psychol Med. 2006;36(12):1727-1735.

53. Strom M, Mortensen EL, Halldorsson TI, et al. Fish and long chain n-3 polyunsaturated fatty acid intakes during pregnancy and risk of postpartum depression: a prospective study based on a large national birth cohort. Am J Clin Nutr. 2009;90:149-155.

54. Hibbeln JR, Davis JM, Steer C, et al. Maternal seafood consumption in pregnancy and neurodevelopmental outcomes in childhood (ALSPAC study): an observational cohort study. Lancet. 2007; 369:578-585.

55. Otto SJ, de Groot RH, Hornstra G. Increased postpartum depressive symptoms is associated with slower normalization after pregnancy of the functional docosahexaenoic acid status. Prstaglandins Leukot Essent Fatty Acids. 2003;69:237-243.

56. Doornbos B, van Goor SA, Dijick-Brouwer DAJ, et al. Supplementation of a low dose of DHA or DHA + AA does not prevent peripartum depressive symptoms in a small population based sample. Prog Neuropsychopharmacol. 2009;33:49-52.

57. Freeman MP, Hibbeln JR, Wisner KL, et al. Randomized dose ranging pilot trial of omega-3 fatty acids for postpartum depression. Acta Psychiatry Scand. 2006;113(1):31-35.

58. Freeman MP, Davis M, Sinha P, et al. Omega-3 fatty acids and supportive psychotherapy for perinatal depression: a randomized placebo controlled study. J Affect Disord. 2008;110(1-2): 142-148.

59. Llorente AM, Jensen CL, Voigy RG, et al. Effect of maternal docosahexaenoic acid supplementation on postpartum depression and information processing. Am J Obstet Gynecol. 2003;188(5):13481353.

60. Makrides M, Gibsom RA, McPhee AJ, et al, and DOMInO Investigative Team. Effect of DHA supplementation during pregnancy on maternal depression and neurodevelopment of young children. JAMA. 2010;304(15):1675-1683.

61. Rees AM, Austin MO, Parker GB. Omega-3 fatty acids as a treatment for perinatal depression: randomized double blind placebo controlled trial. Aust Z J Psychiatry. 2008;42(3):199-205.

62. $\mathrm{Su}$.

63. Rao JS, Rapoport SI. Mood-stabilizers target the brain arachidonic acid cascade. Curr Mol Pharmacol. 2009;2(2):207-214.

64. Chen CT, Green JT, Orr SK, et al. Regulation of brain polyunsaturated fatty acid uptake and turnover. Prostaglandins Leukotr Essent Fatty Acids. 2008;79:85-91.

65. Naoghiul S, Hibbeln JR. Cross-national comparisons of seafood consumption and rates of bipolar disorder. Am J Psychiatry. 2003;160(12):2222-2227.

66. Chiu CC, Huang SY, Su KP, et al. Polyunsaturated fatty acid deficits in patients with bipolar mania. Eur Neuropsychopharmacol. 2003;13:99-103.

67. Ranjekar PK, Hinge A, Hedge MV, et al. Decreased antioxidant enzymes and membrane essential polyunsaturated fatty acids in schizophrenic and bipolar mood disorder patients. Psychiatr Res. 2003;121:109-122.

68. Igarashi M, Ma K, Gao F, et al. Brain lipid concentrations in bipolar disorder. J Psychiatr Res. 2010;43(3):177-186. 
69. Clayton EH, Hanstock TL, Hirneth SJ, et al. Long chain omega-3 polyunsaturated fatty acids in the blood of children and adolescents with juvenile bipolar disorder. Lipids. 2008;43: 1031-1038.

70. Clayton EH, Hanstock TL, Hirneth SJ, et al. Reduced mania and depression in juvenile bipolar disorder associated with long chain omega-3 polyunsaturated fatty acid supplementation. Eur J Clin Nutr. 2009;63:1037-1040.

71. Sublette ME, Bosetti F, DeMar JC, et al. Plasma free polyunsaturated fatty acid levels are associated with symptom severity in acute mania. Bipolar Disor. 2007;9(7):759-765.

72. Chiu CC, Huang SY, Chen CC, et al. Omega-3 fatty acids are more beneficial in the depressive phase than the manic phase in patients with bipolar I disorder. J Clin Psychiatry. 2005;66(12): 1613-1614.

73. Frangou S, Lewis M, McCrone P. Efficacy of ethyleicosapentaenoic acid in bipolar depression: randomized double blind placebo controlled study. Br J Psychiatry. 2006;75(4-5): 315-312.

74. Keck PE, Mintz J, McElroy SL, et al. Double blind randomized placebo controlled trials of ethyl-eicosapentaenoate in the treatment of bipolar depression and rapid cycling bipolar disorders. Biol Psychiatry. 2006;60(9):1020-1022.

75. Osher Y, Bersudsky Y, Belmaker RH. Omega-3 eicosapentaenoic acid in bipolar depression: report of a small open label study. J Clin Psychiatry. 2005;66(6):726-729.

76. Marrangell LB, Suppes T, Ketter TA, et al. Omega-3 fatty acids in bipolar disorder: clinical and research considerations. Prostaglandins Leukot Essent Fatty Acids. 2006;75(4-5):315-321.

77. Stoll Al, Severus WE, Freeman MP, et al. Omega-3 fatty acids in bipolar disorder. Arch Gen Psychiatry. 1999;56(5):407-412.

78. Gracious BL, Chirieac MC, Costescu S, et al. Randomized placebo controlled trial of flax oil in pediatric depression. Bipolar Disord. 2010;12:142-154.

79. Wozniak J, Biederman J, Mick E, et al. Omega-3 fatty acid monotherapy for pediatric bipolar disorder: a prospective open label trial. Eur Neuropsychopharmacol. 2007;17(6-7):440-447.

80. Emsley R, Oosthuizen P, van Rensburh SJ. Clinical potential of omega-3 fatty acids in the treatment of schizophrenia. CNS Drugs. 2003;17(15):1081-1091.

81. Horrobin DF, Glen AI, Vaddadi K. The membrane hypothesis of schizophrenia. Schizophr Res. 1994;13(3):195-201.

82. Fenton WS, Hibbeln J, Knable M. Essential fatty acids, lipid membrane abnormalities, and the diagnosis and treatment of schizophrenia. Biol Psychiatry. 2000;47(1):8-21.

83. Piomelli D, Pilon C, Giros B, et al. Dopamine activation of the arachidonic acid cascade as a basis for D1/D2 receptor synergism. Nature. 1991;353(6340):164-167.

84. Gysin R, Kraftsik R, Sandell J, et al. Impaired glutathione synthesis in schizophrenia: convergent genetic and functional evidence. Proc Natl Acad Sci U S A. 2007;104(42):16621-16626.

85. Prabakaran S, Swatton JE, Ryan MM, et al. Mitochondrial dysfunction in schizophrenia: evidence of compromised brain metabolism and oxidative stress. Mol Psychiatry. 2004;9(7):684-697.

86. Peet M, Laugharne J, Rangarajan N, et al. Depleted red blood cell membrane essential fatty acids in drug treated schizophrenics. J Psychiatr Res. 1995;29(3):227-232.
87. Mahadik SP, Mukherjee S, Horrobin DF, et al. Plasma membrane phospholipid fatty acid composition of cultured skin fibroblasts from schizophrenic patients: comparison with bipolar and normal subjects. Psychiatr Res. 1996;63(2-3):133-142.

88. Assies J, Lieverse R, Vreken P, et al. Significantly reduced docosahexaenoic and docosapentaenoic acid concentrations in erythrocyte membranes from schizophrenic patients compared with a carefully matched control group. Biol Psychiatry. 2001;49: 510-520.

89. Vaddadi KS, Gilleard CJ, Soosai E, et al. Schizophrenia, tardive dyskinesia and essential fatty acids. Schizophr Res. 1996;20(3): 287-294.

90. Peet M. International variations in the outcome of schizophrenia and the prevalence of depression in relation to national dietary practices. Br J Psychiatry. 2004:184:404-408.

91. Christensen O, Christensen E. Fat consumption and schizophrenia. Acta Psychiatr Scand. 1988;78(5):587-591.

92. Hedelin M, Lof M, Olsson M, et al. Dietary intake of fish, omega3 , omega- 6 polyunsaturated fatty acids and vitamin $\mathrm{D}$ and the prevalence of psychotic-like symptoms in a cohort of 33,000 women from the general population. BMC Psychiatry. 2010;10:38.

93. Sinclair HM. Deficiencies of essential fatty acids and atherosclerosis et cetera. Lancet. 1956;1:381-383.

94. Amminger GP, Schafer MR, Papageorgiou K, et al. Long chain omega-3 fatty acids for indicated prevention of psychotic disorders: a randomized placebo controlled trial. Arch Gen Psychiatry. 2010;67(2):146-154.

95. Peet M. Eicosapentaenoic acid in the treatment of schizophrenia and depression: rationale and preliminary double blind clinical trial results. Prostaglandins Leukot Essent Fatty Acids. 2003; 69(6):477-485.

96. Arvindakshan M, Ghate M, Ranjekar PK, et al. Supplementation with a combination of omega-3 fatty acids and antioxidants (vitamins E and C) improves the outcome in schizophrenia. Schizophr Res. 2003;62:195-204.

97. Berger GE, Proffitt TM, McConchie M, et al. Ethyleicosapentaenoic acid in first episode psychosis a randomized placebo controlled trial. J Clin Psychiatry. 2007;68(12):1867-1875.

98. Emsley R, Myburgh C, Oosthuizen P, et al. Randomized placebo controlled study of ethyl-eicosapentaenoic acid as supplemental treatment in schizophrenia. Am J Psychiatry. 2002;159(9):15961598.

99. Fenton WS, Dickerson F, Boronow J, et al. A placebo controlled trial of omega-3 fatty acid (ethyl-eicospentaenoic acid) supplement for residual symptoms and cognitive impairment in schizophrenia. Am J Psychiatry. 2001;158:2071-2074.

100. Peet M, Brind J, Ramchand $\mathrm{CN}$, et al. Two double-blind placebo-controlled pilot studies of eicosapentaenoic acid in the treatment of schizophrenia. Schizophr Res. 2001;49(3):243-251.

101. Peet M, Horrobin DF, and E-E Multicentre Study Group. A dose ranging exploratory study of the effects of ethyleicosapentaenoate in patients with persistent schizophrenic symptoms. J Psychiatr Res. 2002;36(1):7-18.

102. Emsley R, Niehaus DJ, Koen L, et al. The effects of eicosapentaenoic acid in tardive dyskinesia: a randomized placebo controlled trial. Schizophr Res. 2006;84(1):112-120. 
103. Emsley R, Niehaus DJ, Oosthuizen PP, et al. Safety of omega-3 fatty acid, eicosapentaenoic acid (EPA) in psychiatric patients: results from a randomized placebo controlled trial. Psychiatr Res. 2008;161(3):284-291.

104. Wolkin A, Jordan B, Peselow E, et al. Essential fatty acid supplementation in tardive dyskinesia. Am J Psychiatry. 1986; 143(7):912-914.

105. McNamara RK, Able J, Jandacek R, et al. Docosahexaenoic acid supplementation increases prefrontal cortex activation during sustained attention in healthy boys: a placebo controlled, dose ranging, functional magnetic resonance imaging study. Am J Clin Nutr. 2010;91:1060-1067.

106. Hibbeln JR, Davis JM, Steer C, et al. Maternal seafood consumption in pregnancy and neurodevelopmental outcomes in childhood (ALSPAC study): an observational cohort study. Lancet. 2007;369:578-585.

107. Raz R, Gabis L. Essential fatty acids and attention deficit hyperactivity disorder: a systematic review. Dev Med Chil Neurol. 2009;51:580-592.

108. Antalis CJ, Stevens LJ, Campbell M, et al. Omega-3 fatty acid status in attention-deficit/hyperactivity disorder. Prostaglandins Leukot Essent Fatty Acids. 2006;75(4-5):299-308.

109. Kidd PM. Omega-3 DHA and EPA for cognitive, behavior, and mood: clinical findings and structural functional synergies with cell membrane phospholipids. Alt Med Rev. 2007;12(3): 207-227.

110. Stevens LJ, Zentall SS, Abate ML, et al. Omega-3 fatty acids in boys with behavior, learning and health problems. Physiol Behav. 1996;59:915-920.

111. Young GS, Maharaj NJ, Conquer JA. Blood phospholipid fatty acid analysis of adults with and without attention deficit/hyperactivity disorder. Lipids. 2004;39(2):117-123.

112. Aman MG, Mitchell EA, Turbott SH. The effects of essential fatty acid supplementation by Efamol in hyperactive children. J Abnorm Child Psychol. 1987;15:75-90.

113. Arnold LE, Kley-Kamp D, Votolato MA, et al. Gamma linolenic acid for attention deficit hyperactivity disorder: placebo controlled comparison to d-amphetamine. Biol Psychiatry. 1989;25(2):222-228.

114. Brue AW, Oakland TD, Evans RA. The use of a dietary supplement combination and an essential fatty acid as an alternative and complementary treatment for children with attention-deficit/ hyperactivity disorder. Sci Rev Altern Med. 2001;5(4):187-194.

115. Harding KL, Judah RD, Gant C. Outcomes based comparison of Ritalin versus food supplement treated children with AD/HD. Altern Med Rev. 2003;8:319-330.

116. Hirayama S, Hamazaki T, Terasawa K. Effects of docosahexaenoic acid containing food administration on symptoms of attention deficit/hyperactivity disorder: placebo controlled double blind study. Eur J Nutr. 2004;58:467-473.

117. Itomura M, Hamazaki K, Sawazaki S, et al. The effect of fish oil on physical aggression in school children: a randomized double blind placebo controlled trial. J Nutr Biochem. 2005; 16(3):163-171.

118. Johnson M, Ostlund S, Fransson G, et al. Omega-3/omega-6 fatty acids for attention deficit hyperactivity disorder: a randomized placebo controlled trial in children and adolescents. $J$ Affect Disord. 2009;12(5):394-401.
119. Raz R, Carasso RL, Yehuda S. The influence of short chain essential fatty acids on children with attention deficit/hyperactivity disorder: a randomized placebo controlled study. J Child Adolesc Psychopharmacol. 2009;19:167-177.

120. Richardson AJ, Montgomery P. The Oxford-Durham study: a randomized controlled trial of dietary supplementation with fatty acids in children with developmental coordination disorder. Pediatrics. 2005;115:1360-1366.

121. Richardson AJ, Puri BK. A randomized double blind placebo controlled study of the effects of supplementation with highly unsaturated fatty acids on ADHD-related symptoms in children with specific learning disabilities. Prog Neuropsychopharmacol Biol Psychiatry. 2002;26:233-239.

122. Sinn N, Bryan J. Effect of supplementation with polyunsaturated fatty acids and micronutrients on learning and behavior problems associated with childhood ADHD. J Dev Behav Pediatr. 2007;28:82-91.

123. Stevens L, Zhang W, Peck L, et al. EFA supplementation in children with inattention, hyperactivity and other disruptive behaviors. Lipids. 2003;38(10):1007-1021.

124. Voigt RG, LlorenteAM, Jensen CL, et al. A randomized double blind placebo controlled trial of docosahexaenoic acid supplementation in children with attention deficit/hyperactivity disorder. J Pediatr. 2001;139(2):189-196.

125. Vaisman N, Kaysar N, Zaruk-Adasha Y, et al. Correlation between changes in blood fatty acid composition and visual sustained attention performance in children with inattention: effect of dietary n-3 fatty acids containing phospholipids. Am J Clin Nutr. 2008;87(5):1170-1180.

126. Antalis CJ, Stevens LJ, Campbell M, et al. Omega-3 fatty acid status in attention-deficit/hyperactivity disorder. Protaglandin Leukot Essent Fatty Acids. 2006;75(4-5):299-308.

127. Sander JL. Qualitative differences between Asperger's disorder and autism? Historical considerations. J Autism Dev Disord. 2009;39(11):1560-1567.

128. National Institute of Health (2010). Autism Spectrum Disorders. http://www.nichd.nih.gov/health/topics/asd.cfm. Accessed January $25,2010$.

129. Ozonoff S, Iosif A, Baguio F, et al. A prospective study of the emergence of early behavioral signs of autism. J Am Acad Child Adolesc Psychiatry. 2010;49(3):256-266, e1-e2.

130. Mandell DS, Novak MM, Zubritsky CD. Factors associated with age of diagnosis with autism spectrum disorders. Pediatrics. 2005;116(5):1480-1486.

131. James SJ, Cutler P, Melnyk S, et al. Metabolic biomarkers of increased oxidative stress and impaired methylation capacity in children with autism. Am J Clin Nutr. 2004;80(6):1611-1617.

132. Ross MA. Could oxidative stress be a factor in neurodevelopmental disorders? Prostaglandin Leukot Essent Fatty Acids. 2000;63: 61-64.

133. Malik M, Sheikh AM, Wen G, et al. Expression of inflammatory cytokines, Bcl 2 and cathepsin D are altered in lymphoblast of autistic subjects. Immunobiology. 2011;216(1-2):80-85.

134. Kim HY, Akbar M, Kim KY. Inhibition of neuronal apoptosis by polyunsaturated fatty acids. $J$ Mol Neurosci. 2001;16(2-3): 223-227. 
135. Kim HY, Akbar M, Lau A. Effects of docosapentaenoic acid on neuronal apoptosis. Lipids. 2003;38(4):453-457.

136. Orr SK, Bazinet RP. The emerging role of docosahexaenoic acid in neuroinflammation. Curr Opin Investig Drugs. 2008;9(7): 735-743.

137. Ahmad SO, Park JH, Radel JD, et al. Reduced numbers of dopamine neurons in the substantia nigra pars compacta and ventral segmental area of rats fed an omega-3 polyunsaturated fatty acid-deficient diet: a stereological study. Neurosci Lett. 2008;438(3):3030-3307.

138. Wainwright PE. Dietary essential fatty acids and brain function: a developmental perspective on mechanisms. Proc Nutr Soc. 2002;61:61-69.

139. Kootz JP, Marinelli B, Cohen DJ. Modulation of response to environmental stimulation in autistic children. J Autism Dev Disord. 1982;12(2):185-193.

140. Clark T, Feehan C, Tinline C. Autistic symptoms in children with attention deficit-hyperactivity disorder. Eur Child Adolesc Psychiatry. 1999;8(1):50-55.

141. Ponde MP, Novaes CM, Losapio MF. Frequency of symptoms of attention deficit and hyperactivity disorder in autistic children. Arq Neuropsiquiatr. 2010;68(1):103-106.

142. Ronald A, Simonoff E, Kuntsi J, et al. Evidence for overlapping genetic influences on autistic and ADHD behaviors in a community twin sample. J Child Psychol Psychiatry. 2008; 49:535-542.

143. Vancassel S, Durand G, Barthelemy C, et al. Plasma fatty acid levels in autistic children. Prostaglandins Leukot Essent Fatty Acids. 2001;65(1):1-7.

144. Wiest MM, German JB, Harvey DJ. Plasma fatty acid profiles in autism: a case-control study. Prostaglandins Leukot Essent Fatty Acids. 2009;80(4):221-227.

145. Sliwinski S, Croonenberghs J, Christophe A, et al. Polyunsaturated fatty acids: do they have a role in the pathophysiology of autism? Neuroendocrinol Lett. 2006;27(4):465-471.

146. McNamara R, Jandacek R, Rider T, et al. Chronic risperidone normalizes elevated pro-inflammatory cytokine and C-reactive protein production in omega-3 fatty acid deficient rats. Eur $J$ Pharmacol. 2011;652(1-3):152-156.

147. McNamara R, Able J, Jandacek R, et al. Chronic risperidone treatment preferentially increases rat erythrocyte and prefrontal cortex omega-3 fatty acid composition: evidence for augmented biosynthesis. Schizophr Res. 2009;107(2-3):150-157.

148. Gagliano A, Germanò E, Pustorino G, et al. Risperidone treatment of children with autistic disorder: effectiveness, tolerability, and pharmacokinetic implications. $J$ Child Adolesc Psychopharmacol. 2004;14(1):39-47.

149. Bell JG, MacKinlay EE, Dick JR, et al. Essential fatty acids and phospholipase A2 in autistic spectrum disorders. Prostaglandins Leukot Essent Fatty Acids. 2004;71:201-204.

150. Bu B, Ashwood P, Harvey D, et al. Fatty acid compositions of red blood cell phospholipids in children with autism. Prostaglandins Leukot Essent Fatty Acids. 2006;74:215-221.

151. Johnson CR, Handen BL, Zimmer M, et al. Polyunsaturated fatty acid supplementation in young children with autism. J Dev Phys Disabil. 2009;22:1-10.
152. Politi P, Cena H, Comelli M, et al. Behavioral effects of omega-3 fatty acid supplementation in young adults with severe autism: an open label study. Arch Med Res. 2008;39:682-685.

153. Meiri G, Bichovsky Y, Belmaker RH. Omega-3 fatty acid treatment in autism. J Child Adolesc Psychopharmacol. 2009;19(4):449-451.

154. Meguid NA, Atta HM, Gouda AS, et al. Role of polyunsaturated fatty acids in the management of Egyptian children with autism. Clin Biochem. 2008;41:1044-1048.

155. Patrick L, Salik R. Study report. Benefits of essential fatty acid supplementation on language and learning skills in children with autism and Asperger's syndrome. http:/gapsaustralia.com.au/ wpcontent/uploads/2010/03/PatrickStudy05.pdf. Accessed February $28,2011$.

156. Amminger GP, Berger GE, Schafer MR, et al. Omega-3 fatty acids supplementation in children with autism: a double-blind randomized placebo-controlled pilot study. Biol Psychiatry. 2007;61:551-553.

157. Schoene NW. Vitamin E and omega-3 fatty acids: effectors of platelet responsiveness. Nutrition. 2001;17:793-796.

158. Yehuda S, Rabinowitz S, Mostofsky DI. Mixture of essential fatty acids lowers test anxiety. Nutr Neurosci. 2005;8:265-267.

159. Canitano R, Scandurra V. Psychopharmacology in autism: an update. Prog Neuropsychopharmacol Biol Psychiatry. 2011; 35(1):18-28.

160. Buydens-Branchey L, Branchey M, Hibbeln JR. Association between increases in plasma n-3 polyunsaturated fatty acids following supplementation and decreases in anger and anxiety in substance abusers. Prog Neuropsychopharmacol Biol Psychiatry. 2008;32:568-575.

161. Fux M, Benjamin J, Nemets B. A placebo controlled cross over trial of adjunctive EPA in OCD. J Psychiatr Res. 2004;38: 323-325.

162. Zeev K, Michael M, Ram K, et al. Possible deleterious effects of adjunctive omega-3 fatty acids in post traumatic stress disorder patients. Neuropsychiatr Dis Treat. 2005;1:187-190.

163. Matsuoka Y, Nishi D, Yonemoto N, et al. Omega-3 fatty acids for secondary prevention of post traumatic stress disorder after accidental injury: an open-label pilot study. J Clin Psychopharmacol. 2010;30(2):217-219.

164. Jacobs MN, Santillo D, Johnston PA, et al. Organochlorine residues in fish oil dietary supplements: a comparison of industrial grade oils. Chemosphere 1998;37:1709-1721.

165. Chiuchiolo AL, Dickhut AL, Cochran MA, et al. Persistant organic pollutants at the base of the antartic marine food web. Environ Sci Technol. 2004;38(13):3551-3557.

166. EPA-823-R-04-005: What you need to know about mercury in fish and shellfish. 2004. http://www.fda.gov/Food/FoodSafety/ProductSpecificInformation/Seafood/FoodbornePathogensContaminants/ Methylmercury/ucm115662.htm. Accessed June 21, 2011.

167. Bent S, Bertoglio K, Ashwood P, et al. A pilot randomized controlled trial of omega-3 fatty acids for autism spectrum disorder. J Autism Dev Disord. 2010;41:545-554; http://www.springerlink .com/content/gh8166v881105751/fulltext.pdf. Accessed February $6,2011$.

168. Hilbert G, Lillemark L, Balchen S, et al. Reductions of organochlkorine contaminants from fish oil during refining. Chemosphere. 1998;37:1241-1252. 